OPEN ACCESS

Edited by:

Brian Dixon,

University of Waterloo, Canada

Reviewed by:

Javier Santander,

Memorial University of Newfoundland,

Canada

Yamila Carpio,

Center for Genetic Engineering and

Biotechnology (C/GB), Cuba

*Correspondence:

Zun-Lan Luo luozunlan@163.com

Kai-Jian We

kiwei@mail.hzau.edu.cn

Specialty section:

This article was submitted to

Comparative Immunology,

a section of the journal

Frontiers in Immunology

Received: 04 November 2020

Accepted: 18 January 2021

Published: 26 February 2021

Citation:

Zhou X, Zhang G-R, Ji W, Shi Z-C,

Ma X-F, Luo Z-L and Wei K-J (2021)

The Dynamic Immune Response of Yellow Catfish (Pelteobagrus

fulvidraco) Infected With

Edwardsiella ictaluri Presenting the Inflammation Process.

Front. Immunol. 12:625928.

doi: 10.3389/fimmu.2021.625928

\section{The Dynamic Immune Response of Yellow Catfish (Pelteobagrus fulvidraco) Infected With Edwardsiella ictaluri Presenting the Inflammation Process}

\author{
Xu Zhou ${ }^{1,2,3}$, Gui-Rong Zhang ${ }^{1,2}$, Wei $\mathrm{Ji}^{1,2}$, Ze-Chao Shi ${ }^{4}$, Xu-Fa Ma ${ }^{1,2}$, Zun-Lan Luo ${ }^{3 *}$ \\ and Kai-Jian Wei ${ }^{1,2^{*}}$ \\ ${ }^{1}$ National Demonstration Center for Experimental Aquaculture Education, Huazhong Agricultural University, Wuhan, China, \\ 2 Key Laboratory of Freshwater Animal Breeding, Ministry of Agriculture and Rural Affairs, College of Fisheries, Huazhong \\ Agricultural University, Wuhan, China, ${ }^{3}$ State Key Laboratory of Environmental Criteria and Risk Assessment, Chinese \\ Research Academy of Environmental Sciences, Beijing, China, ${ }^{4}$ Key Laboratory of Freshwater Biodiversity Conservation, \\ Ministry of Agriculture and Rural Affairs, Yangtze River Fisheries Research Institute, Chinese Academy of Fishery Sciences, \\ Wuhan, China
}

Edwardsiella ictaluri is a highly destructive pathogen in cultured yellow catfish, thus it was very necessary to study the immune response of yellow catfish against bacterial infection. In this study, RNA-Seq technology was used to study the immune response in two distinct tissues of yellow catfish at eight different time points (h) after E. ictaluri infection. The number of differentially expressed genes (DEGs) in the spleen and liver was low at $3 \mathrm{~h}$ and $6 \mathrm{~h}$ post-infection, respectively. Afterwards, the most number of DEGs in the spleen was detected at $72 \mathrm{~h}$, while the number of DEGs in the liver maintained a high level from $24 \mathrm{~h}$ to $120 \mathrm{~h}$. The GO and KEGG enrichment analyses of DEGs at different time points uncovered that cytokines were continuously transcribed at $6 \mathrm{~h}$ to $120 \mathrm{~h}$; whereas the liver is the main organ that secretes the components of the complement system, and metabolic regulation was activated from $12 \mathrm{~h}$ to $120 \mathrm{~h}$. Moreover, an overview of the inflammation response of yellow catfish was exhibited including pattern-recognition receptors, inflammatory cytokines, chemokines, complements, and inflammation-related signal pathways. The similar expression tendency of nine genes by qRT-PCR validated the accuracy of transcriptome analyses. The different transcriptomic profiles obtained from the spleen and liver will help to better understand the dynamic immune response of fish against bacterial infection, and will provide basic information for establishing effective measures to prevent and control diseases in fish.

Keywords: transcriptome, bacteria, Edwardsiella ictaluri, yellow catfish, inflammation 


\section{INTRODUCTION}

RNA-Seq technology, as a powerful tool, has been widely exploited to study gene expression profiling in both physiological and pathological conditions $(1,2)$. In recent years, transcriptome analyses about immune response against bacterial infection have been performed in various fishes (3-22). Several pathogenic bacteria (e.g. Aeromonas hydrophila, Edwardsiella tarda, Vibrio alginolyticus) and some tissues (e.g. spleen, liver, head kidney) were commonly used as sources of infection and target tissues in fish transcriptome analyses, respectively (23). After bacterial infection, complement system, pattern recognition pathways, antigen processing and presentation pathway, and $\mathrm{B}$ cell and $\mathrm{T}$ cell receptor signaling pathway can be activated in various fishes (23). Though these studies have revealed the immune mechanism of fish underlying the bacteria-infection process, there has been limited information to use transcriptome analysis to study the dynamic immune process of fish in time and space.

Yellow catfish (Pelteobagrus fulvidraco), an important commercial freshwater species, is very popular as food in China, Japan, South Korea and Southeast Asia (24). With the increasing market demand in China, the aquaculture of yellow catfish has developed rapidly in recent years. However, bacterial diseases and parasitoses often outbreak and have caused great economic losses (25). Edwardsiella ictaluri, a Gram-negative rodshaped bacterium, was reported to cause severe ascites disease, enteric septicemia and crack-head disease in yellow catfish (26, 27). In mammals, inflammation is a protective response of the organism when host cells sense evolutionarily conserved structures through germline-encoded pattern-recognition receptors (PRRs) (28). Once inflammatory processes are triggered, large amounts of pro-inflammatory cytokines are released, such as tumor necrosis factor (TNF), interleukin-1 $\beta$ (IL-1 $\beta$ ), interferon- $\gamma$ (IFN- $\gamma$ ), interleukin-17 (IL-17), and interleukin-22 (IL-22) (28). Chemokines are messengers of innate immunity, and they can recruit leukocytes into tissues at the site of infection to prevent and eliminate pathogens (29). Besides, the complement system is an important and efficient immune defense mechanism, which mediates microbial opsonization and killing, and generates inflammatory peptides such as C3a and C5a (28). In teleosts, the inflammatory mechanisms are not clear underlying the bacteria-infection process. Thus, it is necessary to understand the inflammatory process against bacterial infection and establish effective measures to prevent and control diseases in yellow catfish.

In recent years, there have been a few researches about the transcriptome of yellow catfish after stimulants and bacteria stimulation. A comparative transcriptome analysis between wild and albino yellow catfish provided important basic information for comparative genomics, evolution, and genetic breeding in this species (30). After stimulation by lipopolysaccharide (LPS) and polyriboinosinic polyribocytidylic acid (poly I:C) for $12 \mathrm{~h}$, transcriptomic analysis of yellow catfish liver observed 370 differentially expressed genes (DEGs) including 18 immune response genes, and 522 DEGs including 13 immune response genes, respectively $(31,32)$. Transcriptome profile of yellow catfish spleen following E. ictaluri challenge for $72 \mathrm{~h}$ detected 172 immune
DEGs that were enriched into the immune response-related pathways (pattern recognition receptor, complement and coagulation cascades, T-cell receptor and B-cell receptor signaling pathways) (22). Although the above transcriptome studies analyzed the immune response and potential molecular mechanism of yellow catfish against bacterial infection based on a single tissue at one treatment time point, it is necessary to further investigate the dynamic immune response of yellow catfish against bacteria based on several tissues at different time points post-infection. The spleen is an important immune organ that not only has a large number of macrophages and neutrophils but also can generate a lot of cytokines and chemokines against pathogenic infection (33). The liver links host defense with metabolic readjustments and plays a dual role in immune function and metabolism upon pathogen challenge (34). In this study, the transcriptomic profiles were obtained by RNA-Seq technology from the spleen and liver tissues of yellow catfish at $0 \mathrm{~h}$ (control), and $3 \mathrm{~h}, 6 \mathrm{~h}, 12 \mathrm{~h}, 24 \mathrm{~h}$, $48 \mathrm{~h}, 72 \mathrm{~h}$, and $120 \mathrm{~h}$ after infection with E. ictaluri. This study aims to understand the dynamic immune response of yellow catfish against bacterial infection and to explore the process of the inflammatory response against bacterial infection.

\section{MATERIALS AND METHODS}

\section{Fish Collection}

Healthy juvenile individuals of yellow catfish (one-year-old, $14 \mathrm{~g}$ ) were obtained from the fish breeding base of Huazhong Agricultural University (HZAU). Before bacterial infection, the fishes were acclimatized to laboratory conditions in two circulating water tanks by keeping the temperature at $27 \pm 1^{\circ} \mathrm{C}$ and were fed a commercial diet (Hubei Haid Feeds Company, Wuhan, China) twice a day (09:00 and 16:00).

\section{Experimental Infections and Sampling Procedures}

The bacteria (E. ictaluri) for immune challenge experiments were obtained from the fish immunology laboratory of HZAU, and were cultured on brain-heart infusion (BHI) (Becton, Dickinson and Company, USA) and incubated $12 \mathrm{~h}$ at $28{ }^{\circ} \mathrm{C}$ in the incubator. Subsequently the bacteria were washed and suspended in phosphate-buffered saline (PBS, $\mathrm{pH}$ 7.2) to a final concentration of $5 \times 10^{6} \mathrm{CFU} / \mathrm{mL}$. Each fish in the experimental group was intraperitoneally injected with $50 \mu \mathrm{L}$ of suspended E. ictaluri (i.e. $2.5 \times 10^{5} \mathrm{CFU} /$ fish) and each fish in the control group was injected with the same volume of PBS. Twelve fishes were randomly sampled from the experimental group at $3,6,12,24,48,72$, and 120 h post-injection of E. ictaluri and from the control group at 0 hours, every four fishes were as a group of biological duplication. The sampled fish were euthanatized with $300 \mathrm{mg} / \mathrm{L}$ MS-222, and then the spleen and liver tissues were collected for RNA extraction. All tissues were immediately frozen in liquid nitrogen and stored at $-80{ }^{\circ} \mathrm{C}$ until RNA extraction. All infection experiments and sample collections adhered to the standard biosecurity and institutional safety procedures of HZAU. 


\section{RNA Extraction and cDNA Synthesis}

Total RNA was extracted from various tissues using Trizol Reagent (Invitrogen, USA) according to the manufacturer's instruction. The quality of total RNA was checked by $1 \%$ agarose gel electrophoresis. The concentration of total RNA was determined using a Nanodrop ND-2000 spectrophotometer (Thermo Electron Corporation, USA). The first-strand cDNA was generated using the Revert Aid $^{\mathrm{TM}}$ M-MLV Reverse Transcriptase Kit (Promega, USA) following the manufacturer's instructions. The cDNA products were stored at $-20^{\circ} \mathrm{C}$.

\section{RNA Sequencing and Mapping Procedures}

RNA samples were packed in dry ice and shipped to the Majorbio Biotech Co., Ltd. (Shanghai, China) for further analysis. The RNA-seq libraries were prepared using protocols supplied with the TruSeq ${ }^{\mathrm{TM}}$ RNA sample preparation Kit (Illumina, San Diego, CA, USA). FASTX-Toolkit (http://hannonlab.cshl.edu/fastx toolkit/) was used to evaluate the quality of every sample. SeqPrep (https://github.com/jstjohn/SeqPrep) and Sickle (https://github.com/najoshi/sickle) were used to filter out reads with adaptors and low-quality reads from raw data to generate clean data. The clean reads were assembled using Trinity (https://github.com/trinityrnaseq/trinityrnaseq). Highquality RNA sequences were obtained after filtration by TransRate (http://hibberdlab.com/transrate/) and CD-HIT (http://weizhongli-lab.org/cd-hit/). The assembled integrity of transcriptome was assessed by BUSCO (http://busco.ezlab.org). High-quality RNA-Seq reads were mapped with the clean reads.

\section{Identification of Differentially Expressed Genes}

To identify differentially expressed genes (DEGs), cleaned, mapped and counted datasets obtained from experimental groups were compared to the control group $(0 \mathrm{~h})$. Only the genes with more than 10 reads in at least one of the individual libraries were applied to DEGs analyses using DESeq2 package. Finally, DEGs with adjusted $P \leq 0.05$ and $\mid \log _{2}$ (fold-change) $\mid \geq 1$ were considered as the targets for further analyses. The data of transcriptome were annotated using GO (BLAST2GO) and KEGG (KOBAS) database. The enrichment analyses of GO and KEGG were performed using Goatools and Python softwares, respectively.

\section{Bioinformatic Analysis}

The complete sequence of the open reading frame (ORF) of each target gene was found using ORF Finder (http://www.ncbi.nlm.nih. gov/projects/gorf/). The protein structure of each target gene was predicted by Simple Modular Architecture Research Tool (SMART) (http://smart.embl-heidelberg.de/). ClustalW program in MEGA 6.06 and BoxShade (http://www.ch.embnet.org/software/BOX_ form.html) was used for multiple sequence alignments.

\section{Analysis of Gene Expression by Quantitative Real-Time PCR (qRT-PCR)}

qRT-PCR was used to detect mRNA expression levels of selected DEGs in the spleen and liver using a 6300 RT-PCR system (Applied Biosystems, USA). The gene-specific primer pairs for
qRT-PCR were designed based on the RNA sequences of selected DEGs (Supplemental Table 1). The $\beta$-actin gene was used as an internal control gene. The PCR reaction mixture consisted of 10 $\mu \mathrm{L}$ LightCycler ${ }^{\circledR} 480$ SYBR Green I Master (Roche, Germany), 7 $\mu \mathrm{L} \mathrm{ddH}_{2} \mathrm{O}, 2 \mu \mathrm{L}$ cDNA (3 times dilution of a template) and $0.5 \mu \mathrm{L}$ of either gene-specific primer $(10 \mu \mathrm{M})$ in a total volume of $20 \mu \mathrm{L}$. The qRT-PCR of each sample was performed in triplicate according to the following conditions: $95{ }^{\circ} \mathrm{C}$ for $10 \mathrm{~min}$, followed by 40 cycles at $95{ }^{\circ} \mathrm{C}$ for $15 \mathrm{~s}$, annealing temperature for $30 \mathrm{~s}$ and $72{ }^{\circ} \mathrm{C}$ for $30 \mathrm{~s}$. At the end of each PCR reaction, amplification curve and melting curve analyses were performed to check the integrity of the reaction and the quality of the product, respectively. To compare expressions of selected DEGs, the $2^{-\Delta \Delta C t}$ method was adopted to calculate the relative expression levels of the target genes (35).

\section{RESULTS}

\section{Transcriptomic Sequencing and Raw Reads Data}

Forty-two high-quality cDNA libraries from the liver and spleen were constructed by Illumina Hiseq 2000 sequencing platform (Supplemental Table 2). In the liver samples, the raw reads obtained were between 41,039,960 and 75,135,220. The Q20 and Q30 values of these reads were more than 98 and 95\%, respectively, the error rates were less than $0.024 \%$, and the CG contents were about $48 \%$. In the spleen samples, the raw reads ranged from 44,062,228 to 62,082,818. The Q20 and Q30 quality scores of all reads were more than 97 and $93 \%$, respectively, the error rates were less than $0.027 \%$, and the CG contents were between 45.02 and $52.67 \%$ (Table 1). After filtration, the clean reads were mapped back to yellow catfish sequences, and the mapped rate of each sample was over $82 \%$ in the liver samples and over $75 \%$ in the spleen samples (Supplemental Table 3).

\section{Analysis of Differentially Expressed Genes (DEGs)}

All the clean reads were assembled into 481,943 transcripts with a min length of $201 \mathrm{bp}$, a max length of 10,109 bp and an N50 length of 1,368 bp, and 321,257 unigenes were further assembled (Supplemental Table 4). By comparing the unigenes from the experimental groups with that from the control group based on the criteria for DEGs, we screened 5,540 and 4,161 DEGs in the spleen and liver, respectively (Table 1).

In the spleen samples, the total numbers of up- and downregulated DEGs were 3,630 and 1,924, respectively (Table 1). The total number of DEGs was lower at $3 \mathrm{~h}$ and $6 \mathrm{~h}$ post-infection than that at $12-120 \mathrm{~h}$, and the number of up-regulated DEGs was significantly higher than that of down-regulated DEGs at each time point. Besides, the number of up- and down-regulated DEGs in the spleen was continuously increased and reached the highest level at $72 \mathrm{~h}$ post-infection, except for a slight decline of the up-regulated DEGs at $48 \mathrm{~h}$.

In the liver samples, the total numbers of up- and downregulated DEGs were 2,364 and 1,943, respectively (Table 1). The 
total number of DEGs was also fewer at $3 \mathrm{~h}$ and $6 \mathrm{~h}$ than that at other time points. Furthermore, the proportion of up-regulated DEGs (70.74-79.70\%) was significantly higher than that of down-regulated DEGs (20.30-29.26\%) at $3 \mathrm{~h}, 6 \mathrm{~h}$, and $12 \mathrm{~h}$, while the proportion of up-regulated DEGs (53.17-56.05\%) was slightly higher than that of down-regulated DEGs (43.95$46.83 \%)$ at $24-120 \mathrm{~h}$. The number of up- and down-regulated DEGs in the liver gradually increased to a high level at $24 \mathrm{~h}$, and then hit a peak at $48 \mathrm{~h}$.

\section{Function Analysis of Differentially Expressed Genes (DEGs)}

In total, 3,335 GO annotated DEGs and 943 KEGG annotated DEGs were detected in the spleen, whilst a total of 2,851 and 975 DEGs were annotated by the GO and KEGG database of the liver, respectively (Table 2). Of the total DEGs in the spleen and liver at different time point post-infection, the proportion of GO annotated DEGs was distinctly higher than that of KEGG annotated DEGs.

To investigate the dynamic change of the immune functions at different time points post-infection, GO and KEGG enrichments were performed based on the DEGs with $P$-value $<0.05$ and $\mid \log _{2}$ (fold-change) $\mid \geq 2$ from the spleen and liver, respectively. Fifteen most enriched GO terms $(P<0.01)$ of three subclasses (biological process, cellular component and molecular function) were selected in the spleen and liver at 6-120 h postinfection, respectively (Figures 1 and 2). No GO terms were enriched at $3 \mathrm{~h}$ in both spleen and liver. In the spleen, the majority of GO terms were distributed in the biological processes and molecular functions except for the $48 \mathrm{~h}$ and $72 \mathrm{~h}$ time points
(Figure 1). In the molecular functions, cytokine and chemokine associated GOs were detected from $6 \mathrm{~h}$ to $120 \mathrm{~h}$, G-protein receptorassociated GOs were found at 6 h, 12 h, 24 h, and $120 \mathrm{~h}$. Moreover, in the biological processes, immune response-associated GOs were detected at $12 \mathrm{~h}, 48 \mathrm{~h}$, and $120 \mathrm{~h}$, chemotaxis was found at 12-24 h, metabolic process associated GOs were found at 24-120 h (Figure 1). In the liver, the majority of GOs were distributed in the biological processes and cellular components (Figure 2). Only cytokine activity and chemokine activity were discovered at $6 \mathrm{~h}$. Metabolic process and regulation associated GOs were found at $12-120 \mathrm{~h}$, and reproductive process associated GOs were detected at $24-120 \mathrm{~h}$ in the biological processes. In addition, nucleoplasm, intracellular ribonucleoprotein complex, ribonucleoprotein complex and cytosol were detected at 24-120 h in the cellular component (Figure 2).

According to KEGG enrichment analysis, ten most enriched pathways $(P<0.01)$ were obtained in the spleen and liver at $6-120$ $\mathrm{h}$ post-infection, respectively (Tables 3 and 4). No pathways were enriched at $3 \mathrm{~h}$ in both spleen and liver. In the spleen, hematopoietic cell lineage (map04640) and cytokine-cytokine receptor interaction (map04060) were detected at 6-120 h, chemokine signaling pathway (map04062) was detected at 12 $120 \mathrm{~h}$, TNF signaling pathway (map04668) was discovered at 6$120 \mathrm{~h}$ except for $48 \mathrm{~h}$, complement and coagulation cascades (map04610) was detected at $12 \mathrm{~h}, 72 \mathrm{~h}$, and $120 \mathrm{~h}$, and IL-17 signaling pathway (map04657) was only found at $6 \mathrm{~h}$ and $12 \mathrm{~h}$ (Table 3). In the liver, complement and coagulation cascades (map04610) was detected at 24-120 h, TNF signaling pathway (map04668) was only found at $6 \mathrm{~h}$ and $12 \mathrm{~h}$, IL-17 signaling pathway (map04657) was only detected at $6 \mathrm{~h}$, and Th17 cell differentiation was only found at $12 \mathrm{~h}$ (Table 4). Besides, fat

TABLE 1 | Statistics of differentially expressed genes (DEGs) at different time points following E. ictaluri challenge.

\begin{tabular}{|c|c|c|c|c|c|c|}
\hline Time & \multicolumn{3}{|c|}{ Spleen } & \multicolumn{3}{|c|}{ Liver } \\
\hline $3 h$ & 133 (85.26) & $23(14.74)$ & 156 & 318 (79.70) & 81 (20.30) & 399 \\
\hline $12 \mathrm{~h}$ & $1,192(86.06)$ & 193 (13.94) & 1,385 & $1,025(70.74)$ & 424 (29.26) & 1,449 \\
\hline $24 \mathrm{~h}$ & $1,906(74.71)$ & 645 (25.29) & 2,551 & $1,630(56.05)$ & $1,278(43.95)$ & 2,908 \\
\hline $48 \mathrm{~h}$ & $1,621(68.54)$ & $744(31.46)$ & 2,365 & $1,740(55.27)$ & 1,408 (44.73) & 3,148 \\
\hline Total & 3,630 & 1,924 & 5,540 & 2,364 & 1,943 & 4,161 \\
\hline
\end{tabular}

TABLE 2 | Annotated DEGs in gene ontology (GO) and KEGG database.

\begin{tabular}{|c|c|c|c|c|c|c|}
\hline Time & \multicolumn{3}{|c|}{ Spleen } & \multicolumn{3}{|c|}{ Liver } \\
\hline $3 \mathrm{~h}$ & 156 & 109 (69.87) & 53 (33.97) & 399 & 213 (53.38) & 66 (16.54) \\
\hline $12 \mathrm{~h}$ & 1385 & 863 (62.31) & 213 (15.38) & 1,449 & 929 (64.11) & 328 (22.64) \\
\hline $24 \mathrm{~h}$ & 2,551 & $1,649(64.64)$ & 533 (20.89) & 2,908 & 2,005 (68.95) & 659 (22.66) \\
\hline $48 \mathrm{~h}$ & 2,365 & $1,529(64.65)$ & 319 (13.49) & 3,148 & $2,199(69.85)$ & 715 (22.71) \\
\hline Total & 5,540 & $3,335(60.20)$ & $943(17.02)$ & 4,161 & 2,851 (68.52) & 975 (23.43) \\
\hline
\end{tabular}



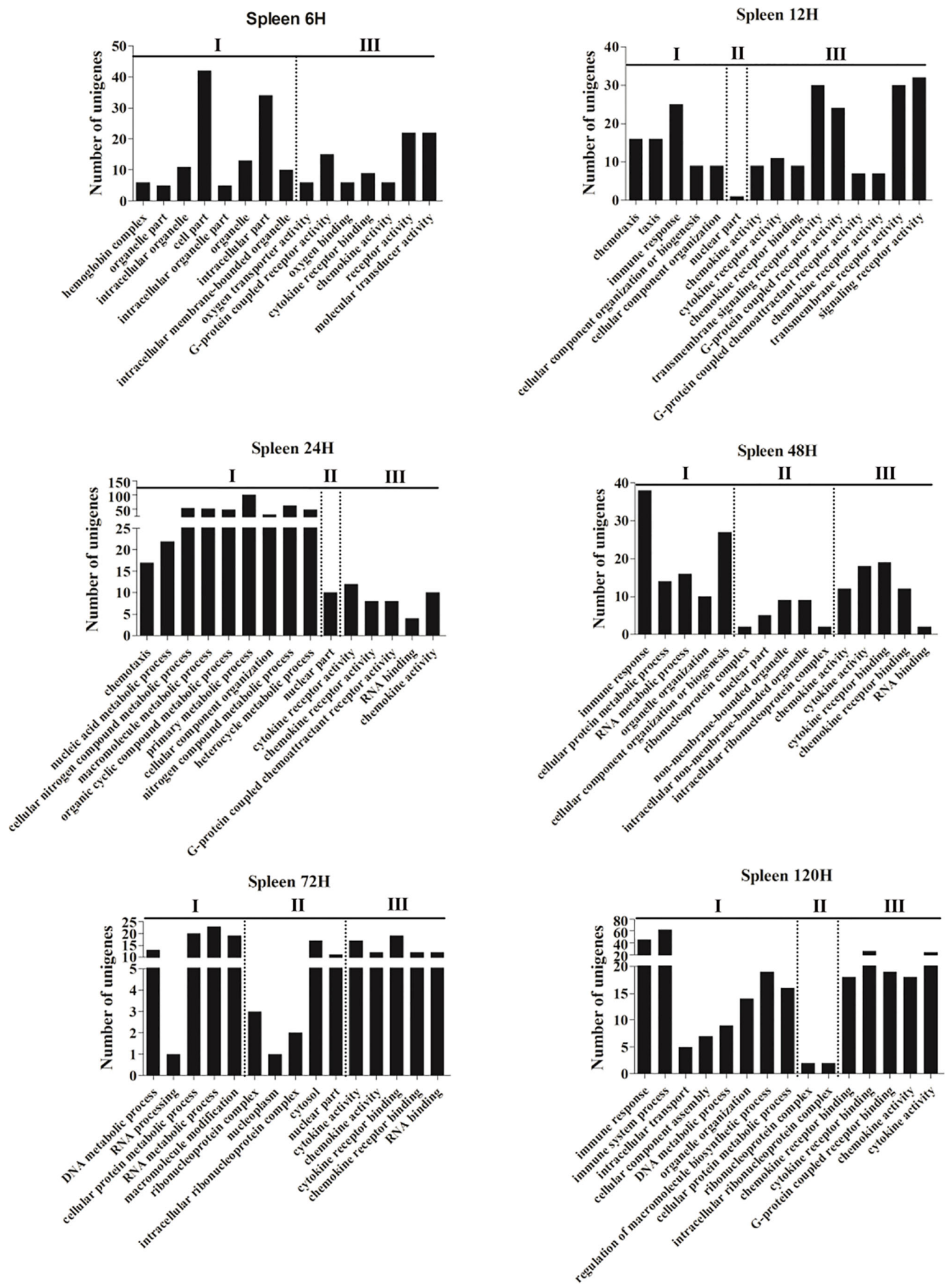

FIGURE 1 | The 15 most enriched GO terms in the spleen of yellow catfish at different time points following E. ictaluri challenge. I: biological process, Il: cellular component, III: molecular function. 
Liver $6 \mathrm{H}$
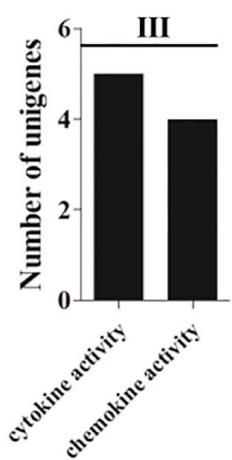

Liver $12 \mathrm{H}$
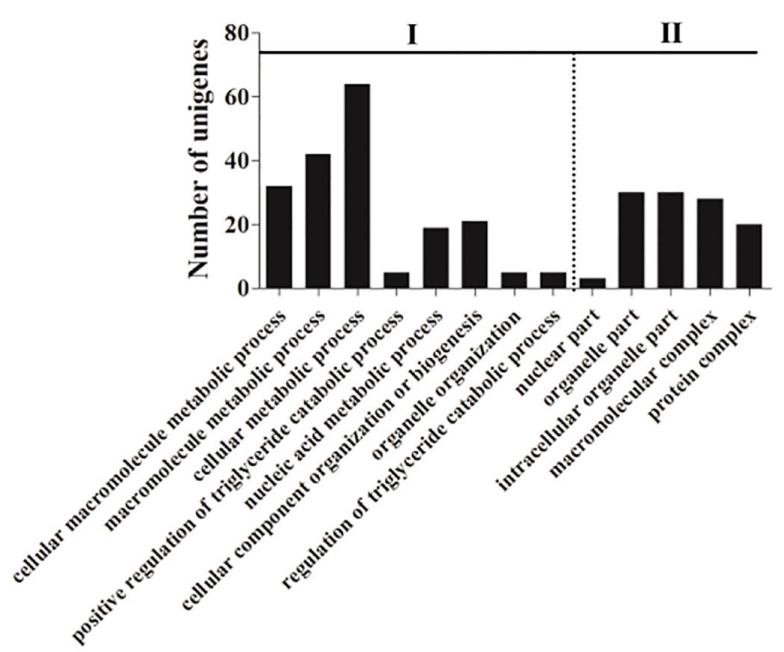

Liver 24H
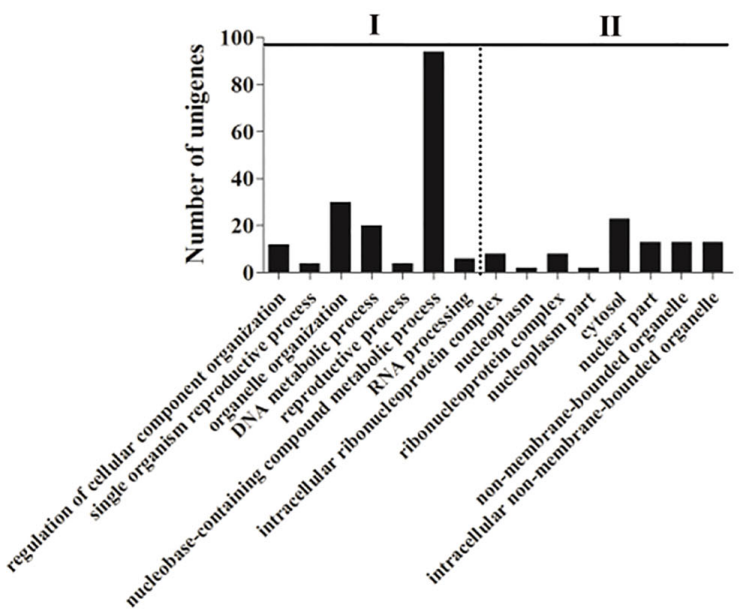

Liver $72 \mathrm{H}$
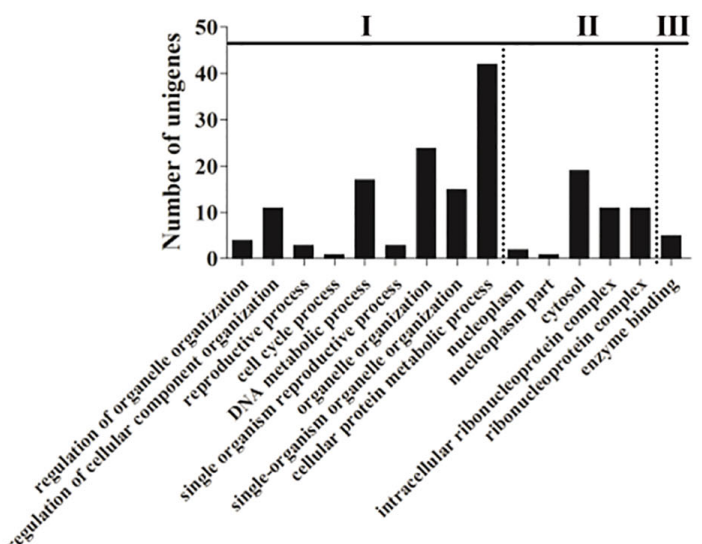

Liver 48H
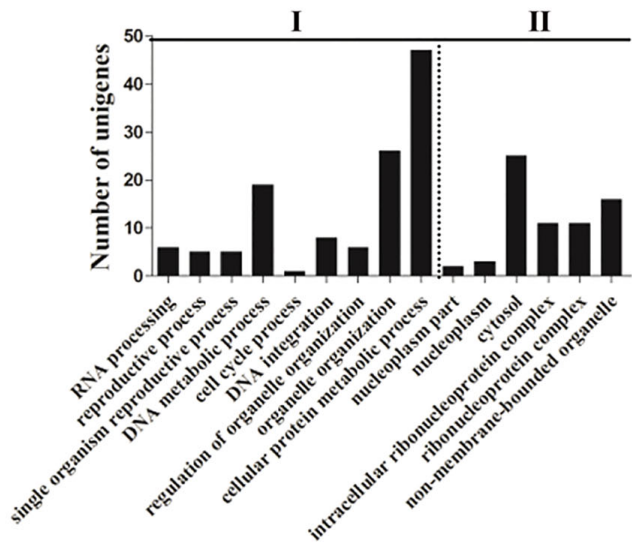

Liver $120 \mathrm{H}$
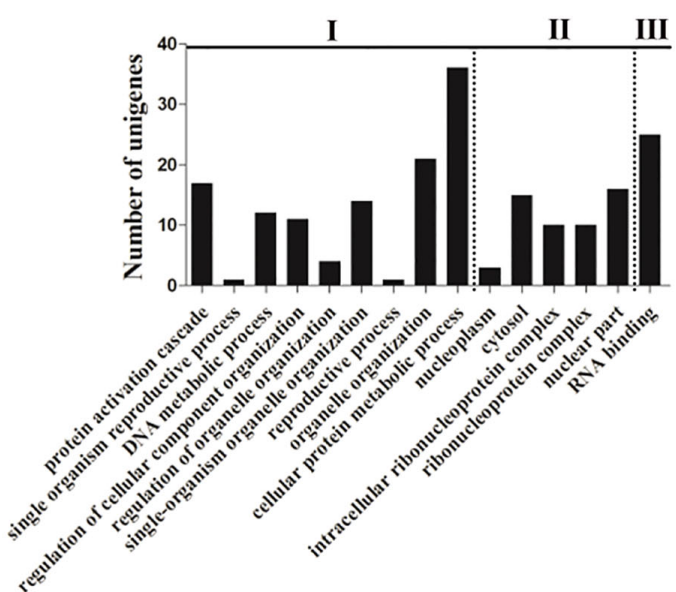

FIGURE 2 | The 15 most enriched GO terms in the liver of yellow catfish at different time points following E. icta/uri challenge. I: biological process, II: cellular component, III: molecular function. 
TABLE 3 | The top 10 enriched KEGG pathways in the spleen at different time points following E. ictaluri challenge.

\begin{tabular}{|c|c|c|c|c|}
\hline Time & Ko id & Term & $\begin{array}{l}\text { Number of } \\
\text { DEGs }\end{array}$ & $P$ value \\
\hline \multirow[t]{7}{*}{$6 h$} & map04640 & Hematopoietic cell lineage & 8 & 2.13E-07 \\
\hline & map04060 & $\begin{array}{l}\text { Cytokine-cytokine receptor } \\
\text { interaction }\end{array}$ & 9 & 6.33E-06 \\
\hline & map05144 & Malaria & 6 & 3.96E-05 \\
\hline & map00524 & $\begin{array}{l}\text { Neomycin, kanamycin and } \\
\text { gentamicin biosynthesis }\end{array}$ & 3 & 0.003885 \\
\hline & map04668 & TNF signaling pathway & 6 & 0.005152 \\
\hline & map05140 & Leishmaniasis & 6 & 0.005512 \\
\hline & map04657 & IL-17 signaling pathway & 6 & 0.005737 \\
\hline \multirow[t]{10}{*}{$12 \mathrm{~h}$} & map04060 & $\begin{array}{l}\text { Cytokine-cytokine receptor } \\
\text { interaction }\end{array}$ & 18 & 0 \\
\hline & map04062 & Chemokine signaling pathway & 17 & 1.95E-08 \\
\hline & map04640 & Hematopoietic cell lineage & 9 & 1.4E-06 \\
\hline & map04668 & TNF signaling pathway & 9 & 0.000269 \\
\hline & map05140 & Leishmaniasis & 9 & 0.000297 \\
\hline & map05120 & $\begin{array}{l}\text { Epithelial cell signaling in } \\
\text { Helicobacter pylori infection }\end{array}$ & 9 & 0.001552 \\
\hline & map05323 & Rheumatoid arthritis & 8 & 0.001825 \\
\hline & map04610 & $\begin{array}{l}\text { Complement and coagulation } \\
\text { cascades }\end{array}$ & 8 & 0.002612 \\
\hline & map04657 & IL-17 signaling pathway & 8 & 0.002848 \\
\hline & map04064 & NF-kappa B signaling pathway & 8 & 0.004825 \\
\hline \multirow[t]{10}{*}{$24 \mathrm{~h}$} & map04060 & $\begin{array}{l}\text { Cytokine-cytokine receptor } \\
\text { interaction }\end{array}$ & 29 & 0 \\
\hline & map04145 & Phagosome & 31 & 0 \\
\hline & map05323 & Rheumatoid arthritis & 21 & 0 \\
\hline & map05120 & $\begin{array}{l}\text { Epithelial cell signaling in } \\
\text { Helicobacter pylori infection }\end{array}$ & 20 & 6.58E-09 \\
\hline & map05110 & Vibrio cholerae infection & 18 & 2.82E-08 \\
\hline & map04062 & Chemokine signaling pathway & 23 & 3.73E-08 \\
\hline & map04640 & Hematopoietic cell lineage & 12 & 5.91E-07 \\
\hline & map04668 & TNF signaling pathway & 15 & 1.37E-06 \\
\hline & map05152 & Tuberculosis & 22 & $5.18 \mathrm{E}-06$ \\
\hline & map04966 & Collecting duct acid secretion & 11 & $5.18 \mathrm{E}-06$ \\
\hline \multirow[t]{10}{*}{$48 \mathrm{~h}$} & map04640 & Hematopoietic cell lineage & 14 & 0 \\
\hline & map04060 & $\begin{array}{l}\text { Cytokine-cytokine receptor } \\
\text { interaction }\end{array}$ & 34 & 0 \\
\hline & map04145 & Phagosome & 32 & 0 \\
\hline & map05323 & Rheumatoid arthritis & 23 & 0 \\
\hline & map04062 & Chemokine signaling pathway & 23 & 1.32E-07 \\
\hline & map05120 & $\begin{array}{l}\text { Epithelial cell signaling in } \\
\text { Helicobacter pylori infection }\end{array}$ & 18 & $3.11 \mathrm{E}-07$ \\
\hline & map05110 & Vibrio cholerae infection & 16 & 9.58E-06 \\
\hline & map05152 & Tuberculosis & 22 & 2.84E-05 \\
\hline & map05164 & Influenza A & 21 & 8.45E-05 \\
\hline & map04966 & Collecting duct acid secretion & 10 & 0.000132 \\
\hline \multirow[t]{10}{*}{$72 \mathrm{~h}$} & map05323 & Rheumatoid arthritis & 23 & 0 \\
\hline & map04640 & Hematopoietic cell lineage & 17 & 0 \\
\hline & map04060 & $\begin{array}{l}\text { Cytokine-cytokine receptor } \\
\text { interaction }\end{array}$ & 33 & 0 \\
\hline & map04145 & Phagosome & 40 & 0 \\
\hline & map04062 & Chemokine signaling pathway & 27 & 8.27E-08 \\
\hline & map05205 & Proteoglycans in cancer & 32 & 2.94E-06 \\
\hline & map05110 & Vibrio cholerae infection & 17 & 9.61E-05 \\
\hline & map04933 & $\begin{array}{l}\text { AGE-RAGE signaling pathway in } \\
\text { diabetic complications }\end{array}$ & 18 & 0.000199 \\
\hline & map04610 & $\begin{array}{l}\text { Complement and coagulation } \\
\text { cascades }\end{array}$ & 15 & 0.000232 \\
\hline & map04210 & Apoptosis & 22 & 0.000300 \\
\hline $120 \mathrm{~h}$ & map04060 & $\begin{array}{l}\text { Cytokine-cytokine receptor } \\
\text { interaction }\end{array}$ & 35 & 0 \\
\hline
\end{tabular}

(Continued)
TABLE 3 | Continued

\begin{tabular}{|c|c|c|c|c|}
\hline Time & Ko id & Term & $\begin{array}{l}\text { Number of } \\
\text { DEGs }\end{array}$ & $P$ value \\
\hline & map05323 & Rheumatoid arthritis & 26 & 0 \\
\hline & map04610 & $\begin{array}{l}\text { Complement and coagulation } \\
\text { cascades }\end{array}$ & 19 & 4.79E-09 \\
\hline & map04145 & Phagosome & 28 & 8.3E-08 \\
\hline & map04640 & Hematopoietic cell lineage & 12 & 3.56E-06 \\
\hline & map04062 & Chemokine signaling pathway & 21 & 1.15E-05 \\
\hline & map05120 & $\begin{array}{l}\text { Epithelial cell signaling in } \\
\text { Helicobacter pylori infection }\end{array}$ & 16 & $3.4 \mathrm{E}-05$ \\
\hline & map04933 & $\begin{array}{l}\text { AGE-RAGE signaling pathway in } \\
\text { diabetic complications }\end{array}$ & 17 & 3.92E-05 \\
\hline & map04668 & TNF signaling pathway & 14 & 7.61E-05 \\
\hline & map05150 & Staphylococcus aureus infection & 10 & 0.000269 \\
\hline
\end{tabular}

digestion and absorption (map04975) was found at 12-120 h, and PPAR signaling pathway (map03320) was enriched notably at 24-120 h (Table 5).

\section{Inflammation-Related Genes of Yellow Catfish Against E. ictaluri Infection}

To analyze the dynamic inflammatory response of yellow catfish against bacterial infection, inflammation-related DEGs were screened in the spleen and liver at different time points after infection of E. ictaluri. The results showed that there were only four DEGs of pattern-recognition receptor found in the spleen and liver after infection (Figure 3). In the spleen, only NACHT, LRR, and PYD domains-containing protein 3 (nlrp3-1) mRNA was significantly up-regulated at $120 \mathrm{~h}(P<0.05)$ (Figure 3A). In the liver, Toll-like receptor 5 membrane $(\operatorname{tl} 5 \mathrm{M})$, nucleotidebinding oligomerization domain-containing protein 1 (nod1) and nlrp3-2 mRNA were significantly up-regulated at 6-120 h, 12-120 h, and $24-120 \mathrm{~h}$, respectively $(P<0.05)$ (Figure 3B). The structure predictions of DEGs showed that the nod1, nlrp3-1 and nlrp3-2 all contained an NAIP, CIIA, HET-E, and TP1 (NACHT) nucleotide binding domain and a leucine-rich repeat (LRR) domain, while the nod1 also had a C-terminal caspase recruitment domain (CARD), and the nlrp3-2 also had a fish-specific NACHT associated domain (FISNA). The tlr5M contained a signal peptide, twelve LRR domains, an LRR C-terminal domain, a transmembrane domain and a TIR domain (Figure 3C).

In total, $29 \mathrm{DEG}$ of chemokine and chemokine receptor were found in the spleen and liver after infection (Figure 4). Firstly, eight CXC chemokines ( $\mathrm{cxcl}$ ) were detected in the spleen and liver (Figure 4). In the spleen, $\mathrm{cxcl} 1$ and $\mathrm{cxcl} 2 \mathrm{mRNAs}$ were notably up-regulated at $3-120 \mathrm{~h}(P<0.05)$, cxcl8 mRNA was only significantly up-regulated at $120 \mathrm{~h}$, whereas other five cxcls (cxcl9, cxcl11.1, cxcl11.6-1, cxcl11.6-2, and cxcl12) mRNAs were significantly up-regulated from $6 \mathrm{~h}$ (or $12 \mathrm{~h}, 48 \mathrm{~h}$ ) to 120 $\mathrm{h}(P<0.05)$ (Figure 4A). In the liver, however, only cxcl $2 \mathrm{mRNA}$ was detected to be up-regulated significantly at $6-120 \mathrm{~h}(P<0.05)$ (Figure 4B). Secondly, a total of eleven CC chemokines (ccl) were found in the spleen and liver (Figure 4). In the spleen, $\mathrm{ccl} 3$ 2, ccl SCYA 101, ccl SCYA 107, and ccl SCYA 114 mRNAs were significantly up-regulated at 3-120 h, ccl19-1 and ccl20 mRNAs were significantly up-regulated from $6 \mathrm{~h}$ and $12 \mathrm{~h}$ to $120 \mathrm{~h}$, and 
TABLE 4 | The top 10 enriched KEGG pathways in the liver at different time points following $E$. ictaluri challenge.

\begin{tabular}{|c|c|c|c|c|}
\hline Time & Ko id & Term & $\begin{array}{l}\text { Number of } \\
\text { DEGs }\end{array}$ & $P$ value \\
\hline \multirow[t]{3}{*}{$6 \mathrm{~h}$} & map04657 & IL-17 signaling pathway & 7 & 3.78E-07 \\
\hline & map04668 & TNF signaling pathway & 5 & 0.000332 \\
\hline & map05134 & Legionellosis & 5 & 0.001277 \\
\hline \multirow[t]{10}{*}{$12 \mathrm{~h}$} & map04380 & Osteoclast differentiation & 15 & 2.54E-08 \\
\hline & map04668 & TNF signaling pathway & 13 & 4.96E-07 \\
\hline & map05162 & Measles & 16 & $1.71 \mathrm{E}-06$ \\
\hline & map04141 & $\begin{array}{l}\text { Protein processing in endoplasmic } \\
\text { reticulum }\end{array}$ & 23 & 1.23E-05 \\
\hline & map05164 & Influenza A & 17 & 1.61E-05 \\
\hline & map04010 & MAPK signaling pathway & 19 & 1.99E-05 \\
\hline & map04975 & Fat digestion and absorption & 8 & 2.98E-05 \\
\hline & map05140 & Leishmaniasis & 11 & 5.75E-05 \\
\hline & map05134 & Legionellosis & 12 & 0.000112 \\
\hline & map04659 & Th17 cell differentiation & 11 & 0.000377 \\
\hline \multirow[t]{10}{*}{$24 h$} & map03320 & PPAR signaling pathway & 26 & 0 \\
\hline & map04141 & $\begin{array}{l}\text { Protein processing in endoplasmic } \\
\text { reticulum }\end{array}$ & 51 & 0 \\
\hline & map04975 & Fat digestion and absorption & 14 & 8.89E-07 \\
\hline & map04610 & $\begin{array}{l}\text { Complement and coagulation } \\
\text { cascades }\end{array}$ & 19 & 3.31E-05 \\
\hline & map05140 & Leishmaniasis & 18 & 0.000166 \\
\hline & map00561 & Glycerolipid metabolism & 18 & 0.000965 \\
\hline & map04933 & $\begin{array}{l}\text { AGE-RAGE signaling pathway in } \\
\text { diabetic complications }\end{array}$ & 20 & 0.001435 \\
\hline & map05134 & Legionellosis & 19 & 0.001854 \\
\hline & map04920 & Adipocytokine signaling pathway & 16 & 0.005000 \\
\hline & map03060 & Protein export & 13 & 0.007140 \\
\hline \multirow[t]{10}{*}{$48 \mathrm{~h}$} & map04610 & $\begin{array}{l}\text { Complement and coagulation } \\
\text { cascades }\end{array}$ & 40 & 0 \\
\hline & map04975 & Fat digestion and absorption & 16 & 3.21E-08 \\
\hline & map03320 & PPAR signaling pathway & 26 & 2.38E-07 \\
\hline & map05150 & Staphylococcus aureus infection & 17 & 4.08E-07 \\
\hline & map00340 & Histidine metabolism & 15 & 4.16E-06 \\
\hline & map00140 & Steroid hormone biosynthesis & 13 & 3.96E-05 \\
\hline & map04933 & $\begin{array}{l}\text { AGE-RAGE signaling pathway in } \\
\text { diabetic complications }\end{array}$ & 24 & $6.65 \mathrm{E}-05$ \\
\hline & map00380 & Tryptophan metabolism & 18 & 0.000127 \\
\hline & map05140 & Leishmaniasis & 18 & 0.001038 \\
\hline & map00561 & Glycerolipid metabolism & 19 & 0.001551 \\
\hline \multirow[t]{10}{*}{$72 \mathrm{~h}$} & map04610 & $\begin{array}{l}\text { Complement and coagulation } \\
\text { cascades }\end{array}$ & 32 & 1.17E-08 \\
\hline & map04975 & Fat digestion and absorption & 16 & 1.42E-08 \\
\hline & map05150 & Staphylococcus aureus infection & 17 & 8.68E-08 \\
\hline & map03320 & PPAR signaling pathway & 22 & 1.54E-05 \\
\hline & map05140 & Leishmaniasis & 19 & $5.25 \mathrm{E}-05$ \\
\hline & map04141 & $\begin{array}{l}\text { Protein processing in endoplasmic } \\
\text { reticulum }\end{array}$ & 41 & 0.001184 \\
\hline & map00561 & Glycerolipid metabolism & 18 & 0.001366 \\
\hline & map05142 & $\begin{array}{l}\text { Chagas disease (American } \\
\text { trypanosomiasis) }\end{array}$ & 21 & 0.001662 \\
\hline & map00340 & Histidine metabolism & 11 & 0.002574 \\
\hline & map05020 & Prion diseases & 11 & 0.003777 \\
\hline \multirow[t]{7}{*}{$120 \mathrm{~h}$} & map05150 & Staphylococcus aureus infection & 18 & 0 \\
\hline & map04610 & $\begin{array}{l}\text { Complement and coagulation } \\
\text { cascades }\end{array}$ & 33 & 0 \\
\hline & map04975 & Fat digestion and absorption & 14 & 3.66E-07 \\
\hline & map05140 & Leishmaniasis & 21 & $4.22 \mathrm{E}-07$ \\
\hline & map03320 & PPAR signaling pathway & 22 & $3.2 \mathrm{E}-06$ \\
\hline & map04933 & $\begin{array}{l}\text { AGE-RAGE signaling pathway in } \\
\text { diabetic complications }\end{array}$ & 22 & 3.51E-05 \\
\hline & map00140 & Steroid hormone biosynthesis & 11 & 0.000285 \\
\hline
\end{tabular}

TABLE 4 | Continued

\begin{tabular}{lllcl}
\hline Time & Ko id & \multicolumn{1}{c}{ Term } & $\begin{array}{c}\text { Number of } \\
\text { DEGs }\end{array}$ & $\boldsymbol{P}$ value \\
& & 16 & 0.000407 \\
map05322 & Systemic lupus erythematosus & 21 & 0.000445 \\
map04974 & Protein digestion and absorption & 20 & 0.000559 \\
map05146 & Amoebiasis & & \\
\hline
\end{tabular}

TABLE 5 | The only 10 inflammation-related signal pathways from all DEGs by KEGG enriched analysis.

\begin{tabular}{llcl}
\hline Ko id & \multicolumn{1}{c}{ Term } & $\begin{array}{c}\text { Number of } \\
\text { DEGs }\end{array}$ & P value \\
\hline map04610 & $\begin{array}{l}\text { Complement and coagulation } \\
\text { cascades }\end{array}$ & 122 & 0 \\
map04010 & MAPK signaling pathway & 117 & $4.09 E-06$ \\
map04621 & NOD-like receptor signaling pathway & 95 & $3.38 \mathrm{E}-05$ \\
map04062 & Chemokine signaling pathway & 93 & $2.25 \mathrm{E}-08$ \\
map04060 & Cytokine-cytokine receptor & 80 & 0 \\
& interaction & & \\
map04670 & Leukocyte transendothelial migration & 67 & 0.000828 \\
map04659 & Th17 cell differentiation & 64 & $1.35 \mathrm{E}-07$ \\
map04612 & Antigen processing and presentation & 60 & $1.17 \mathrm{E}-05$ \\
map04630 & JAK-STAT signaling pathway & 56 & $1.89 \mathrm{E}-05$ \\
map04668 & TNF signaling pathway & 52 & $5.77 \mathrm{E}-06$ \\
\hline
\end{tabular}

ccl3-1 and ccl4 mRNAs only had high expression levels at 72$120 \mathrm{~h}$ and at $120 \mathrm{~h}$, respectively $(P<0.05)$, whereas ccl14 mRNA was notably down-regulated at $24-120 \mathrm{~h}(P<0.05)$ (Figure 4A). In the liver, ccl3-2, ccl SCYA 101 and ccl SCYA 107 mRNAs were significantly up-regulated at 6-120 h, ccl19-1, and ccl19-2 mRNA had high expression levels at 24-120 h $(P<0.05)$, whereas ccl3-1 and ccl18 mRNAs were notably down-regulated at $12-24 \mathrm{~h}$ and at $48-120 \mathrm{~h}$, respectively $(P<0.05)$ (Figure $\mathbf{4 B}$ ). Thirdly, four CXC chemokine receptors (cxcr) were found in the spleen, cxcr1 and cxcr3-2 mRNAs were notably up-regulated at 6-120 h, whereas cxcr4 and cxcr3-1 mRNAs were significantly down-regulated at $6-120 \mathrm{~h}$ and at $24-120 \mathrm{~h}$, respectively $(P<0.05)$ (Figure 4A). Finally, five CC chemokine receptors (ccr) detected in the spleen, of which ccr3 and ccr5 mRNAs were notably up-regulated from $6 \mathrm{~h}$ and $12 \mathrm{~h}$ to $120 \mathrm{~h}$, respectively $(P<0.05)$, whereas ccr4 and ccr7 mRNAs were significantly down-regulated at $24-120 \mathrm{~h}(P<0.05)$, and ccr9 mRNA was significantly down-regulated at $3-120 \mathrm{~h}(P<0.05)$ (Figure 4A). The alignment of protein sequences showed that all chemokines contained four conserved cysteines, two of which near C-terminal formed C-X-C structures called CXCL, or formed conserved C-C structures called CCL (Figures 4C, D). Moreover, the structure predictions showed that all chemokine receptors had a seven-transmembrane (7tm) domain (Figure 4E).

After infection with E. ictaluri, 21 DEGs of inflammatory cytokine and inflammatory cytokine receptor were found in the spleen and liver (Figure 5). Firstly, there were three tumor necrosis factors (tnf) and three tnf receptors (tnfr) detected in the spleen and liver. In the spleen, tnf $\alpha$ and tnfr6b mRNAs were significantly up-regulated at $3-120 \mathrm{~h}(P<0.05)$, and tnfr 1 and tnfr6 mRNAs were significantly up-regulated at $6-120 \mathrm{~h}$, while $\operatorname{tnf} \beta$ and tnf6 mRNAs were notably up-regulated at $48-120 \mathrm{~h}$ and 
A

B

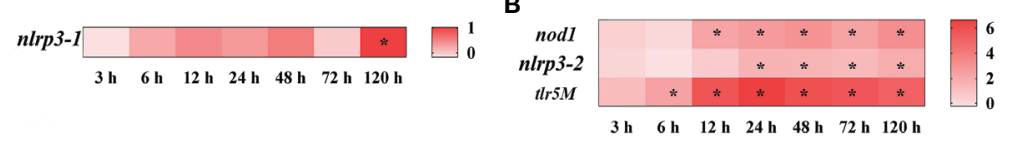

C
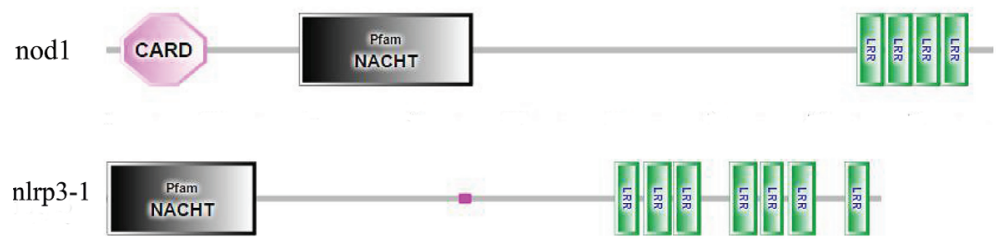

nlrp3-2
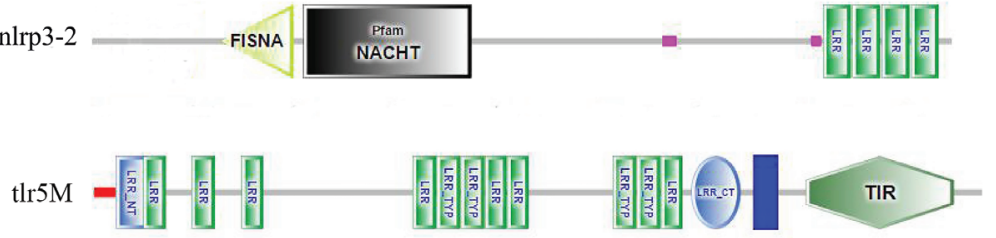

100aa

FIGURE 3 | The DEGs of pattern-recognition receptor in yellow catfish after E. ictaluri infection. (A, B): The DEGs identified in the spleen and liver, respectively. The DEGs of pattern-recognition receptor were analyzed at $3 \mathrm{~h}, 6 \mathrm{~h}, 12 \mathrm{~h}, 24 \mathrm{~h}, 48 \mathrm{~h}, 72 \mathrm{~h}$, and $120 \mathrm{~h}$ post-infection in the spleen and liver. The color gradient represents highly up-regulated (red) to highly down-regulated (white) genes. Significant differences at different time points post-infection compared to the control (0 h) are indicated by asterisks $\left({ }^{*} P<0.05\right)$. (C): Structural features of pattern-recognition receptor DEGs in yellow catfish. The domain organizations were predicted by the SMART online server.

at $24 \mathrm{~h} / 120 \mathrm{~h}$, respectively $(P<0.05)$ (Figure 5A). In the liver, only tnfr6 and tnfr6b mRNAs were significantly up-regulated at 12-120 h $(P<0.05)$ (Figure 5B). The structure predictions of DEGs showed that the $\operatorname{tnf} \alpha, \operatorname{tnf} \beta$ and tnf6 had a typical TNF family domain, the tnfr1 contained a signal peptide, four TNFR family domains, a transmembrane region and a death domain, whereas the tnfr6 only had three TNFR domains compared with the tnfr1 (Figure 5C). Secondly, there were six interleukins (il) and five interleukin receptors (ilr) found in the spleen and liver. In the spleen, il-1 $\beta$, il-12 $\alpha$ and il-6ro mRNAs were notably upregulated at 3-120 h, il-6, il-11, and il-1rI;-1 mRNAs were markedly up-regulated at 6-120 h, il-6r $\beta$, and il-17a/f1 mRNAs were significantly up-regulated from $12 \mathrm{~h}$ and $24 \mathrm{~h}$ to $120 \mathrm{~h}$, respectively $(P<0.05)$, whereas il-12r $\beta$ mRNA was significantly down-regulated at $48-120 \mathrm{~h}(P<0.05)$ and il-34 mRNA was notably up-regulated only at $120 \mathrm{~h}(P<0.05)$ (Figure 5A). In the liver, il-1 $\beta$, il-6r $\beta$, and il-1rI;-2 mRNAs had high expression levels at $6-120 \mathrm{~h}, 12-120 \mathrm{~h}$, and $3 \mathrm{~h}$, respectively $(P<0.05)$ (Figure 5B). Thirdly, colony stimulating factor 1 (csf1), csf1receptor (csf1r), interferon $\gamma($ ifn $\gamma$ ), and ifn $\gamma$ receptor (ifn $\gamma \mathrm{r}$ ) were only detected in the spleen. The ifn $\gamma$ mRNA was significantly up-regulated at 3-120 h with ifn $\gamma \mathrm{r}$ mRNA upregulated at $48-120 \mathrm{~h}(P<0.05)$. The csf1 mRNA was significantly up-regulated at $48-120 \mathrm{~h}$, whereas csf1r mRNA was notably down-regulated at $12-120 \mathrm{~h}(P<0.05)$ (Figure 5A). The structure predictions of DEGs showed that the il- $1 \beta$ had a typical IL-1 family domain, the il-1 receptor type I; (il-1r1) consisted of a signal peptide, two IG-like domains, a transmembrane region and a TIR domain, and the il-1 receptor type II; (il-1r2) contained two IG domains and an IG-like domain (Figure 5C). The il-6 contained a conserved IL- 6 family domain; the il6 r $\alpha$ had an IL-6ra-bind domain, a fibronectin type 3 (FN3) domain and a transmembrane region, and the il-6r $\beta$ comprised four FN3 domains and a transmembrane region (Figure 5C). The il- $12 \alpha$ had a typical IL-12 family domain, and the il-12r $\beta$ contained four FN3 domains and a transmembrane region. The ifn $\gamma$ contained a conserved IFN $\gamma$ family domain, and the ifn $\gamma \mathrm{r} 1$ had a tissue factor domain and a transmembrane region. The csf1 consisted of a CSF-1 family domain and a transmembrane region, and the csflr had a tyrosine protein kinases domain. Furthermore, the il-17a/f1, il-11, and il-34 had an IL-17 family domain, an IL-11 family domain and an IL-34 family domain, respectively (Figure 5C).

Altogether there were 19 complement (c) DEGs detected in the spleen and liver after infection (Figure 6). In the spleen, c3-1, c6 and c7 mRNAs were significantly up-regulated at $12-120 \mathrm{~h}$ $(P<0.05), c 4$, complement factor $(\mathrm{cf}) \mathrm{b} / \mathrm{c}-1$ and cfd mRNAs had high expression levels at two or three time points, respectively $(P<0.05)$, however clq-3 mRNA was notably down-regulated at $48-120 \mathrm{~h}(P<0.05)$ (Figure 6A). In the liver, $\mathrm{c} 7 \mathrm{mRNA}$ was notably up-regulated at $6-120 \mathrm{~h}(P<0.05), \mathrm{clq}-2$ and $\mathrm{cfb} / \mathrm{c}-2$ mRNAs were significantly up-regulated at $12-120 \mathrm{~h}(P<0.05)$, c3-1, c8 $\gamma$ and c9 mRNAs were significantly up-regulated at 24$120 \mathrm{~h}(P<0.05), \mathrm{c} 3-2, \mathrm{c} 4, \mathrm{c} 5$ and $\mathrm{c} 8 \beta$ mRNAs were notably upregulated at two or three time points, respectively $(P<0.05)$, whereas clq-1mRNA was notably down-regulated at all time 
A

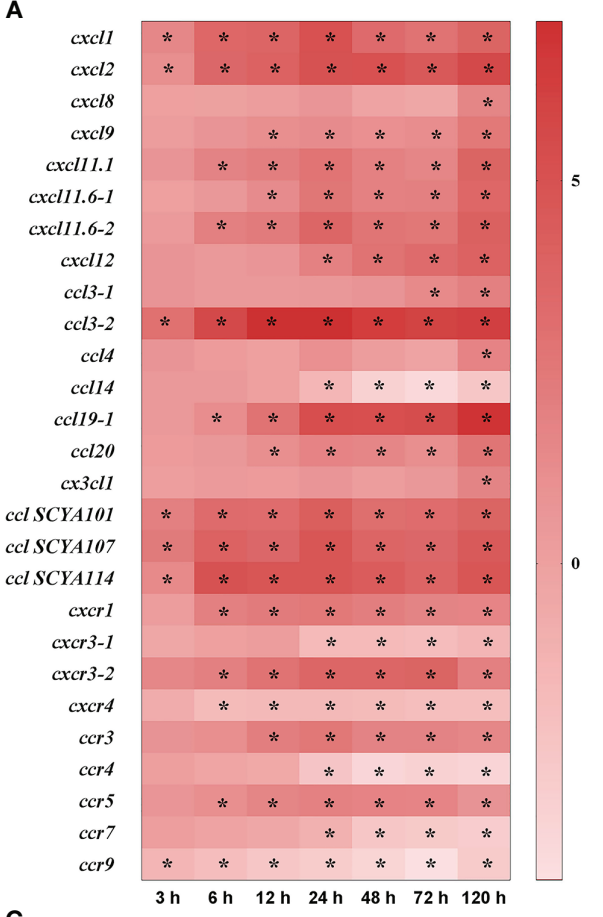

B

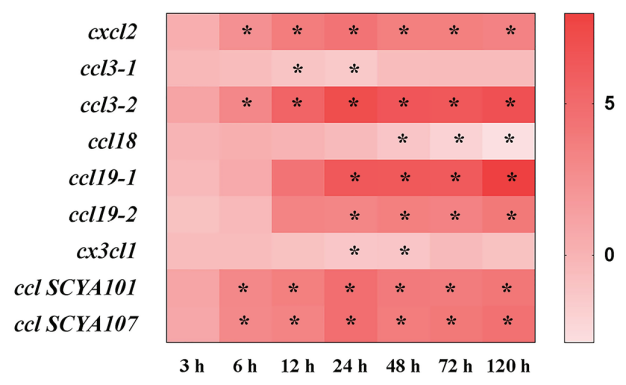

E

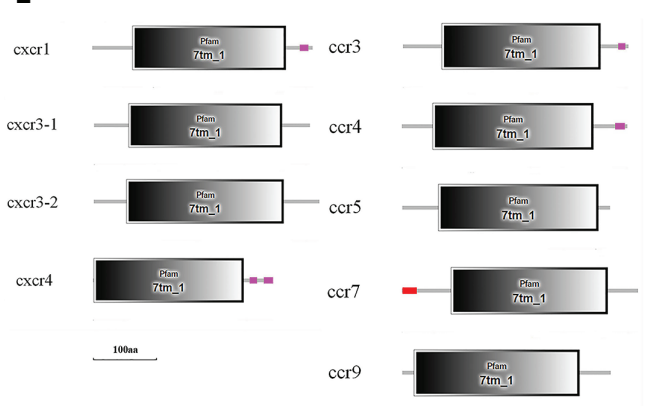

C

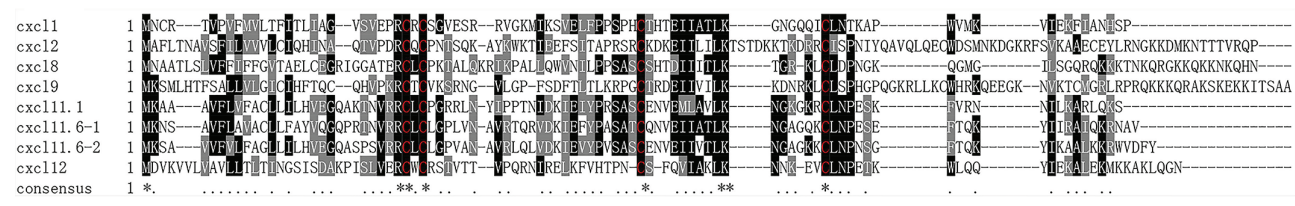

D

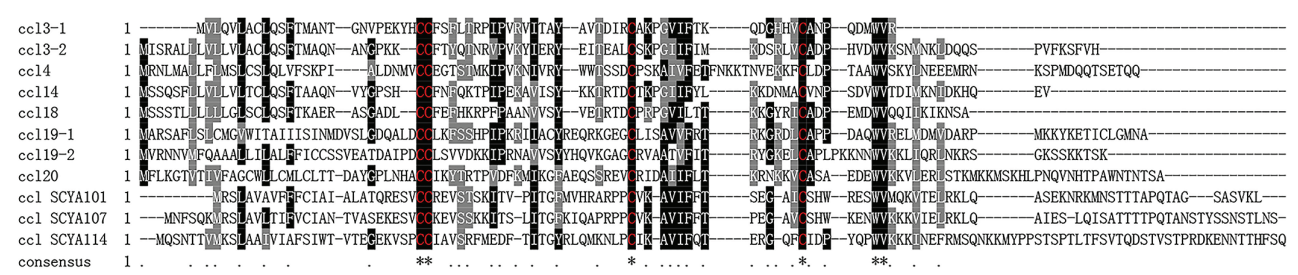

FIGURE 4 | The DEGs of chemokine in yellow catfish after E. ictaluri infection. (A, B): The DEGs identified in the spleen and liver, respectively. The DEGs of chemokine were analyzed at $3 \mathrm{~h}, 6 \mathrm{~h}, 12 \mathrm{~h}, 24 \mathrm{~h}, 48 \mathrm{~h}, 72 \mathrm{~h}$, and $120 \mathrm{~h}$ post-infection in the spleen and liver. The color gradient represents highly up-regulated (red) to highly down-regulated (white) genes. Significant differences at different time points post-infection compared to the control $(0 \mathrm{~h})$ are indicated by asterisks $\left({ }^{\star} P<0.05\right)$. (C, D): Multiple alignments of the deduced amino acid sequences of detected CXCLs and CCLs, respectively. The amino acid sequences of these genes were predicted using MEGA 6.06. ClustalW program in MEGA 6.06 and BoxShade were used for multiple sequence alignments. Similar amino acid residues are marked as grey shadow and identical residues as black shadow. Absent amino acids are indicated by dashes (-). (E): Structural features of chemokine receptor DEGs in yellow catfish. The domain organizations were predicted by the SMART online server.

points except at $72 \mathrm{~h}(P<0.05), \mathrm{clq}-3$ and masp $2 \mathrm{mRNAs}$ were significantly down-regulated at $24-120 \mathrm{~h}(P<0.05)$, cfb mRNA was significantly down-regulated at $48-120 \mathrm{~h}(P<0.05)$, and $\mathrm{c} 1 \mathrm{~s}$, c1r and masplmRNAs were notably down-regulated at one or two time points after $48 \mathrm{~h}$ of infection, respectively $(P<0.05)$ (Figure 6B). The structure predictions of DEGs showed that three clq homologous genes (c1q-1, clq-2, clq-3) contained a complement component C1Q domain, the c1r had a CUB domain, two complement control protein (CCP) domains and a trypsin-like serine protease (Tryp_SPc) domain, and the cls consisted of two CUB domains, a calcium-binding EGF-like domain, two CCP domains and a Tryp_SPc domain (Figure 6C). The c3-1 and c4 comprised four alpha-2-Macroglobulin (A2M) domains, an $\mathrm{A} 2 \mathrm{M}$ receptor (A2M recep) domain, an anaphylatoxin homologous (ANATO) domain and a netrin Cterminal (C345C) domain, the c5 contained three A2M domains, an $\mathrm{A} 2 \mathrm{M}$ receptor domain, three ANATO domains and a C345C domain, and the c3-2 only had two A2M domains and an ANATO domain (Figure 6C). The c6, c7, c8 $\beta$, and $c 9$ all contained a membrane-attack complex perforin (MACPF), and the $c 8 \gamma$ had a 
A

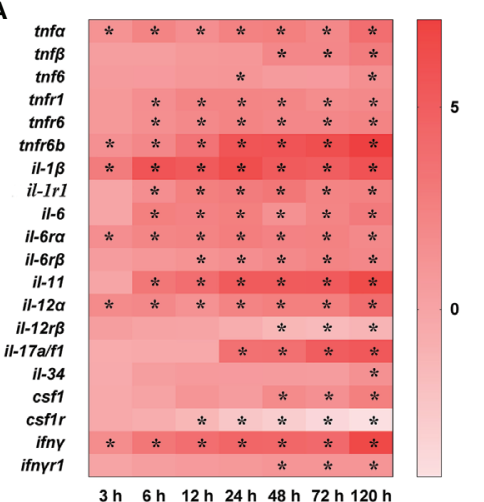

C $\operatorname{tnf} \alpha$

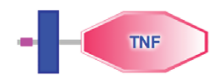
$\operatorname{tnf} \beta$
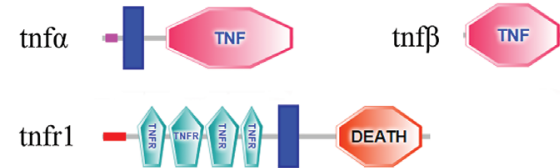

tnfr6b

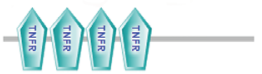

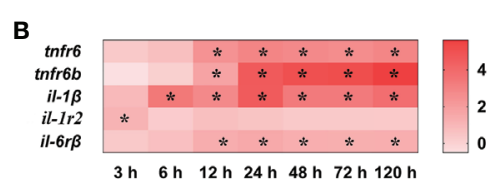

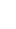
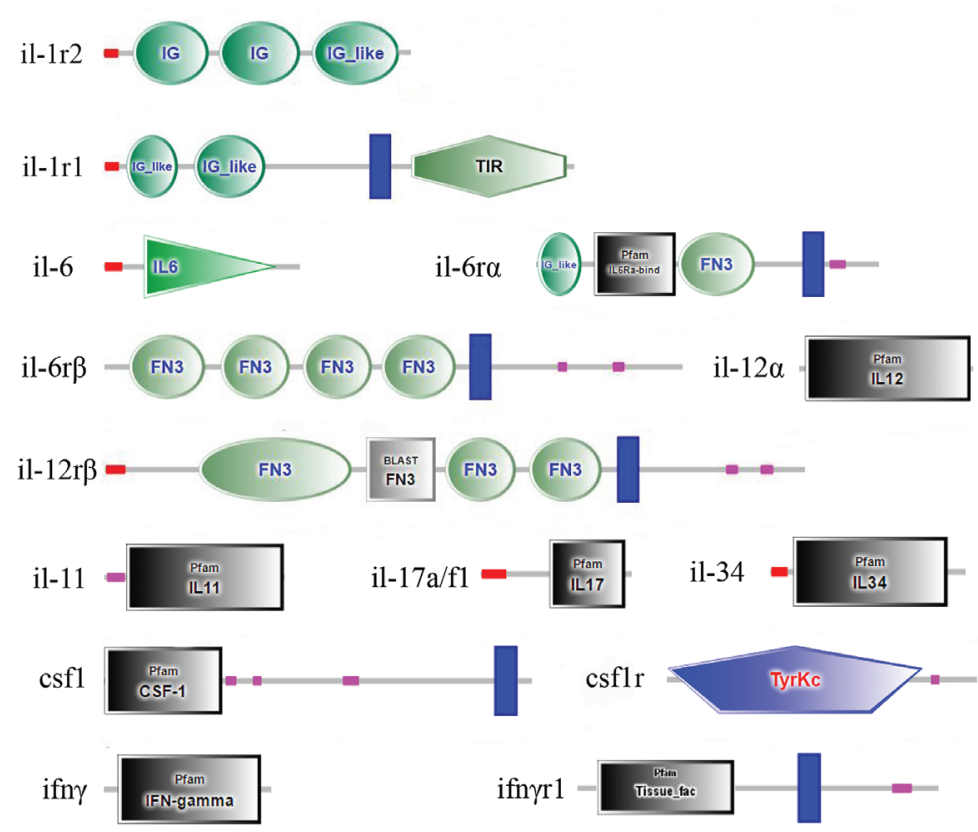

FIGURE 5 | The DEGs of inflammatory cytokine in yellow catfish after E. ictaluri infection. (A, B): The DEGs identified in the spleen and liver, respectively. The DEGs of inflammatory cytokine were analyzed at $3 \mathrm{~h}, 6 \mathrm{~h}, 12 \mathrm{~h}, 24 \mathrm{~h}, 48 \mathrm{~h}, 72 \mathrm{~h}$ and $120 \mathrm{~h}$ post-infection in the spleen and liver. The color gradient represents highly upregulated (red) to highly down-regulated (white) genes. Significant differences at different time points post-infection compared to the control (0 h) are indicated by asterisks ( $\left.{ }^{*} P<0.05\right)$. (C): Structural features of inflammatory cytokine DEGs in yellow catfish. The domain organizations were predicted by the SMART online server.

lipocalin domain. The $\mathrm{cfb} / \mathrm{cl}, \mathrm{cfb}$, and cfd all had a trypsin-like serine protease (Tryp_SPc) domain, the $\mathrm{cfb} / \mathrm{cl}, \mathrm{cfb} / \mathrm{c} 2$, and $\mathrm{cfb}$ all contained a von Willebrand type A (VWA) domain, and the $\mathrm{cfb} / \mathrm{c} 2$ and $\mathrm{cfb}$ also comprised three CCP domains (Figure 6C). The masp1 consisted of two CUB domains, a calcium-binding EGF-like domain, two CCP domains and a Tryp_SPc domain, the masp2 was similar to the masp1, but it only had a CUB domain (Figure 6C).

In total, 13 important adaptor molecule DEGs were found in the spleen and liver after infection (Figure 7). In the spleen, ripk2 (receptor-interacting serine/threonine-protein kinase 2) mRNA was significantly up-regulated at 6-120 h, and tradd (tumor 
A
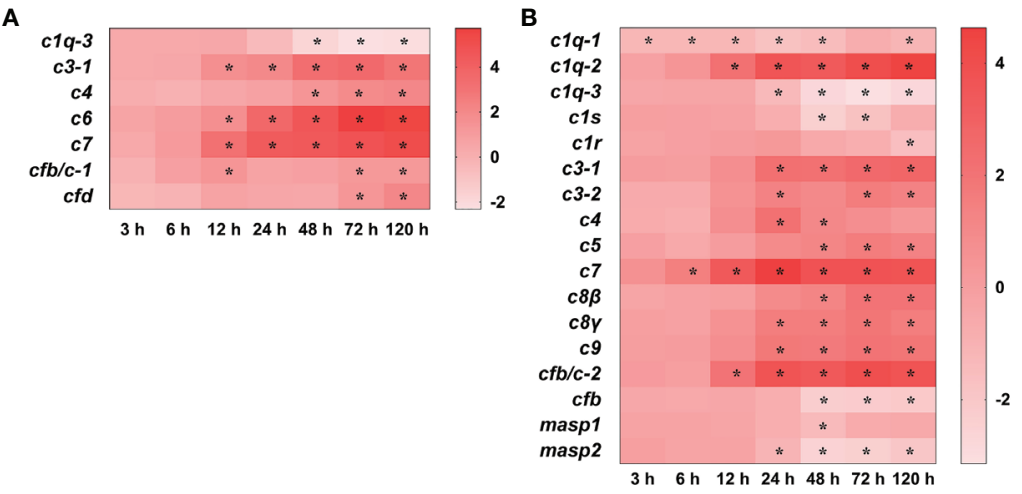

c

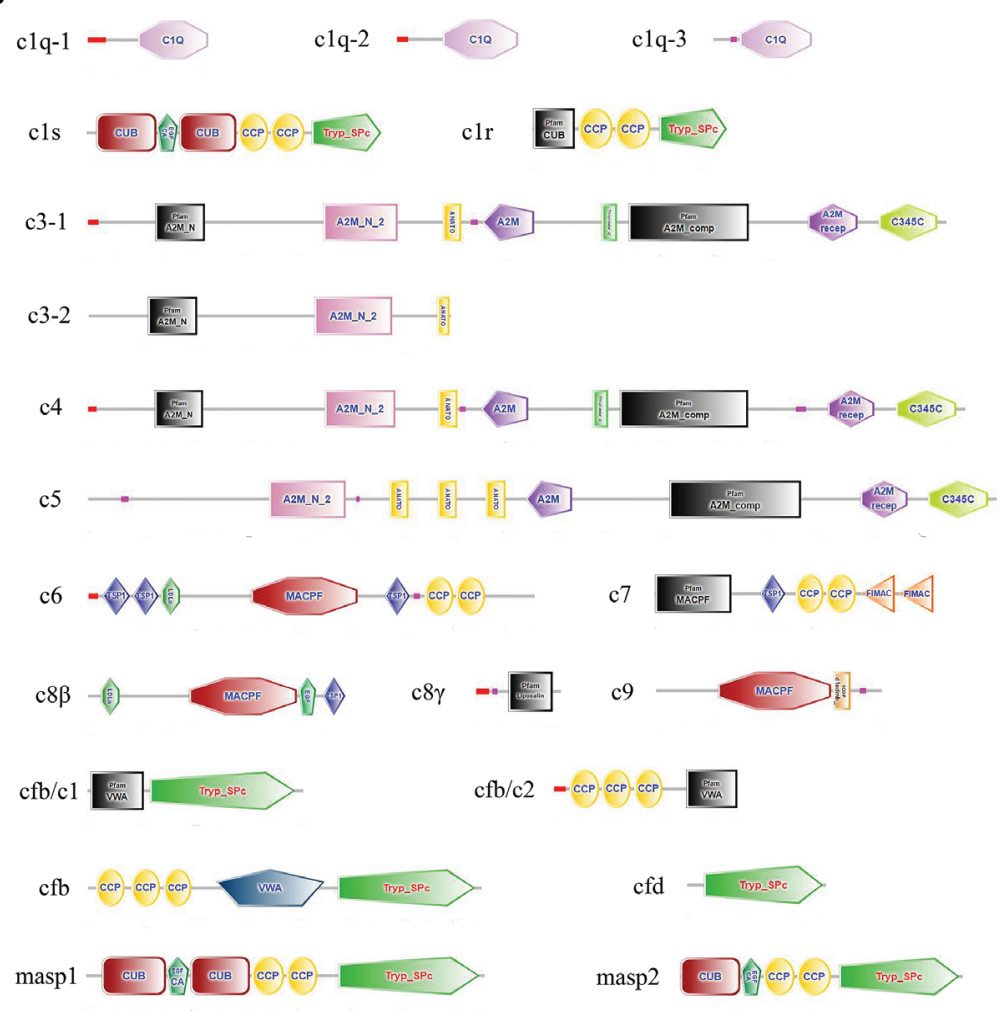

FIGURE 6 | The DEGs of complement in yellow catfish after E. ictaluri infection. (A, B): The DEGs identified in the spleen and liver, respectively. The DEGs of complement were analyzed at $3 \mathrm{~h}, 6 \mathrm{~h}, 12 \mathrm{~h}, 24 \mathrm{~h}, 48 \mathrm{~h}, 72 \mathrm{~h}$, and $120 \mathrm{~h}$ post-infection in the spleen and liver. The color gradient represents highly up-regulated (red) to highly down-regulated (white) genes. Significant differences at different time points post-infection compared to the control (0 h) are indicated by asterisks $\left({ }^{\star} P<0.05\right)$. (C): Structural features of complement DEGs in yellow catfish. The domain organizations were predicted by the SMART online server.

necrosis factor receptor type 1-associated DEATH domain protein) mRNA was notably up-regulated only at $12 \mathrm{~h}(P<0.05)$. The levels of goi (guanine nucleotide-binding protein $\mathrm{G}(\mathrm{i})$ subunit alpha), g $\beta \gamma$ (guanine nucleotide-binding protein subunit beta-5), myd88 (myeloid differentiation factor 88), traf2 (tumor necrosis factor receptor-associated factor 2) and traf7 mRNAs were notably up-regulated at three or four time points after $24 \mathrm{~h}$ of infection, respectively $(P<0.05)$. The levels of irak3 (interleukin-1 receptorassociated factor 3) and irak4 mRNAs were significantly upregulated at $6-120 \mathrm{~h}$ and at $24 \mathrm{~h}$, respectively, while traf5
mRNA was distinctly down-regulated at $72 \mathrm{~h}(P<0.05)$ (Figure 7A). In the liver, the ripk2, $g \beta \gamma$, and irak4 mRNAs were significantly up-regulated at $12-120 \mathrm{~h}$, act1 (adaptor protein CIKS) and traf1 mRNAs were notably up-regulated at 24-120 h, irak1, and irak3 mRNAs were significantly up-regulated at 12-24 $\mathrm{h}$ and at $3-120 \mathrm{~h}$, respectively $(P<0.05)$, whereas goi mRNA was significantly down-regulated at $24-48 \mathrm{~h}(P<0.05)$ (Figure $7 \mathbf{B})$. The structure predictions of DEGs showed that the ripk2 contained a protein tyrosine kinase domain and a caspase recruitment domain (CARD), and the tradd comprised a TRADD, N-terminal 
A

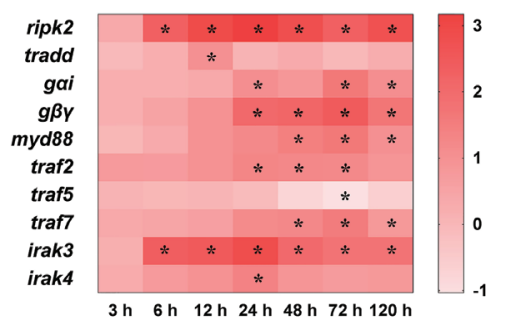

C

ripk2

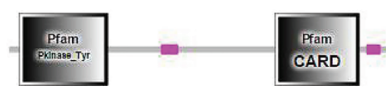

gai

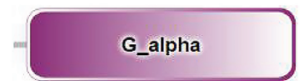

myd88

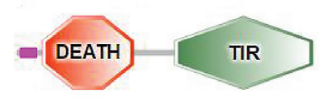

B

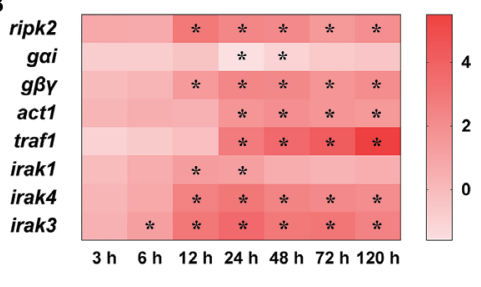

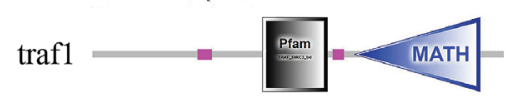

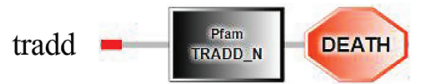

$g \beta \gamma$

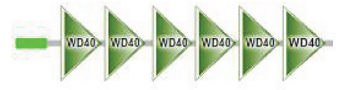

act1 Pfam
SEFIR

$\operatorname{traf} 2$

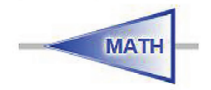

traf5
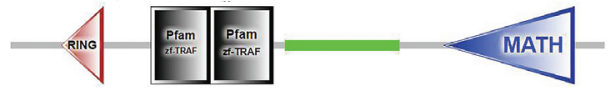

traf7

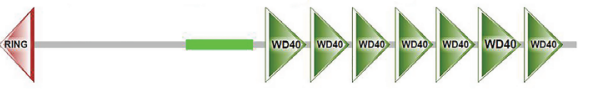

irak1

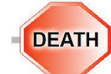

S_TKC

irak3 DEATH

STYKC

irak4

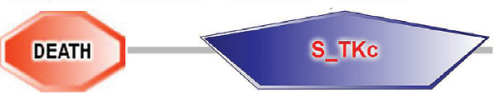

100aa

FIGURE 7 | The DEGs of adaptor molecule in yellow catfish after E. ictaluri infection. (A, B): The DEGs identified in the spleen and liver, respectively. The DEGs of adaptor molecule were analyzed at $3 \mathrm{~h}, 6 \mathrm{~h}, 12 \mathrm{~h}, 24 \mathrm{~h}, 48 \mathrm{~h}, 72 \mathrm{~h}$, and $120 \mathrm{~h}$ post-infection in the spleen and liver. The color gradient represents highly upregulated (red) to highly down-regulated (white) genes. Significant differences at different time points post-infection compared to the control $(0 \mathrm{~h})$ are indicated by asterisks $\left({ }^{*} P<0.05\right)$. (C): Structural features of adaptor molecule DEGs in yellow catfish. The domain organizations were predicted by the SMART online server.

(TRADD_N) domain and a DEATH domain (Figure 7C). The goi contained a G-protein alpha domain, and the g $\beta \gamma$ had six WD domains. The myd88 consisted of a Death domain and a TIR domain, and the act1 had a SEFIR domain. The traf1, traf2, and traf5 all contained a meprin and TRAF homology (MATH) domain, besides, the traf1 had a TRAF_BIRC3_bd domain, the traf5 had a ring finger (RING) domain and two TRAF-type zinc finger (zf-TRAF) domains, and the traf7 consisted of a RING domain and seven WD domains (Figure 7C).The irak1, irak3, and irak4 all had a DEATH domain, while both the irak1 and irak4 also contained a serine/threonine protein kinases domain, and the irak3 also had an unclassified protein kinase domain (Figure 7C).

\section{Inflammation-Related Pathways of Yellow Catfish Against E. ictaluri Infection}

Based on the 8,263 DEGs detected altogether in the spleen and liver, there were only ten pathways enriched significantly associated with the inflammation by KEGG enriched analysis $(P<0.001)$. Among the ten pathways, more DEGs (122 and 117) were enriched into the complement and coagulation cascades (map04610) and the MAPK signaling pathway (map04010), whereas the JAK-STAT signaling pathway (map04630) and the TNF signaling pathway (map04668) were enriched with fewer DEGs (56 and 52), respectively (Table 5). 
The MAPK signaling pathway is an important downstream signal transduction pathway of the inflammatory response, and it consists of ERK, JNK, and p38 signal pathways. In total, nine ERK signaling pathway-related DEGs were detected in the spleen and liver of yellow catfish after infection (Supplemental Figure 1A). In the spleen, GTPase HRas (hras), MAP kinase-interacting serine/ threonine-protein kinase 1 (mknk1), activating transcription factor 4 (creb2) and proto-oncogene c-Fos-like (fos) mRNAs were distinctly up-regulated at four or five time points $(P<0.05)$, son of sevenless homolog 1 (sos) and mitogen-activated protein kinase 1-like (erk) mRNAs were significantly up-regulated only at $72 \mathrm{~h}$ $(P<0.05)$ (Supplemental Figure 1A). In the liver, GTPase NRaslike (kras) mRNA was notably up-regulated at $12-120 \mathrm{~h}(P<0.05)$, and RAF proto-oncogene serine/threonine-protein kinase-like (raf1) and activating transcription factor 4 (creb2) mRNAs were significantly up-regulated at $24 \mathrm{~h}(P<0.05)$, whereas transcriptional regulator Myc-B-like (myc) was significantly down-regulated at 3 $\mathrm{h}$, and proto-oncogene c-Fos-like (fos) mRNA were notably downregulated at all time points except at $12 \mathrm{~h}(P<0.05)$ (Supplemental Figure 1A). A total of $15 \mathrm{JNK}$ and p38 signal pathway-related DEGs were found in the spleen and liver after infection (Supplemental Figure 1B). In the spleen, MAP kinase-activated protein kinase 3-like (mapkapk3), ras-related C3 botulinum toxin substrate 2 (rac2) and cell division control protein 42 homolog (cdc42) mRNAs were significantly up-regulated from $6 \mathrm{~h}$ or $12 \mathrm{~h}$ to $120 \mathrm{~h} \quad(P<0.05)$, two mitogen-activated protein kinase $14 \mathrm{~A}$-like (p38-1 and p38-2) and mitogen-activated protein kinase kinase kinase 8 (cot) mRNAs were significantly induced at two or three time points $(P<0.05)$, and mitogen-activated protein kinase kinase kinase 5 (ask1) was distinctly up-regulated only at $72 \mathrm{~h}(P<0.05)$; whereas mitogen-activated protein kinase kinase kinase kinase 2like (gck) was notably down-regulated at $24-120 \mathrm{~h}(P<0.05)$, dual specificity mitogen-activated protein kinase kinase 4-like (mkk4) and transcription factor AP-1 (ap-1) mRNAs were notably downregulated only at $72 \mathrm{~h}$ and $48 \mathrm{~h}$, respectively $(P<0.05)$ (Supplemental Figure 1B). In the liver, cot was significantly upregulated at 6-120 h, cdc42 and p38-3 mRNAs were notably upregulated at three or four time points, and mitogen-activated protein kinase kinase kinase kinase 4-like (hgk) was significantly up-regulated only at $24 \mathrm{~h}$; whereas ap-1 and transcription factor jun-D-like (jund) mRNAs were significantly down-regulated at all time points $(P<0.05)$, and ras-related $\mathrm{C} 3$ botulinum toxin substrate (rac1) mRNA was significantly down-regulated at $48-120 \mathrm{~h}$ $(P<0.05)$ (Supplemental Figure 1B).

The JAK-STAT signal pathway mediates the downstream signal transduction pathway of IFN- $\gamma$ and chemokine. Nine JAK-STAT signal pathway-related DEGs were detected in the spleen and liver after infection (Supplemental Figure 1B). In the spleen, suppressor of cytokine signaling 3 (socs3) mRNA was significantly up-regulated at all time points $(P<0.05)$, signal transducer and activator of transcription 3 (stat3), signal transducer and activator of transcription 1 (stat1), suppressor of cytokine signaling 1 (socs1), tyrosine-protein kinase JAK2 (jak2) and signal transducer and activator of transcription 2 (stat2) mRNAs were notably induced from $12 \mathrm{~h}$ ( or $24 \mathrm{~h}, 48 \mathrm{~h})$ to $120 \mathrm{~h}(P<0.05)$, whereas signal transducer and activator of transcription 4 (stat4)
mRNA was significantly down-regulated at 24-120 h $(P<0.05)$ (Supplemental Figure 1C). In the liver, tyrosine-protein kinase JAK1 (jak1), stat1, jak2, and stat3 mRNAs were notably upregulated from $6 \mathrm{~h}$ (or $12 \mathrm{~h}, 24 \mathrm{~h})$ to $120 \mathrm{~h}(P<0.05)$, whereas stat2 mRNA was significantly down-regulated at $24-72 \mathrm{~h}(P<0.05)$ (Supplemental Figure 1C).

Additionally, there were seven other DEGs of inflammatory signal pathway detected in the spleen and liver after infection (Supplemental Figure 1D). In the spleen, caspase 3b (casp3) and NF-kappa-B inhibitor alpha-like (ikb $\alpha)$ mRNAs were significantly up-regulated from $3 \mathrm{~h}$ or $6 \mathrm{~h}$ to $120 \mathrm{~h}(P<0.05)$, inhibitor of nuclear factor kappa-B kinase subunit alpha (ikk $\alpha$ ), NF-kappa-B inhibitor beta (ikb $\beta$ ) and caspase 7 (casp7) mRNAs were notably induced at two or three time points, respectively $(P<0.05)$, whereas caspase 1 (casp1) mRNA was significantly down-regulated at $24-120 \mathrm{~h}(P<0.05)$ (Supplemental Figure 1D). In the liver, ikb $\alpha, \mathrm{ikb} \beta$ and caspase 8 (casp8) mRNAs were notably up-regulated from $6 \mathrm{~h}$ (or $12 \mathrm{~h}, 48 \mathrm{~h})$ to $120 \mathrm{~h}(P<0.05)$, respectively. The casp3 mRNA was significantly up-regulated only at $120 \mathrm{~h}(P<0.05)$ (Supplemental Figure 1D).

\section{qRT-PCR Analysis}

We used qRT-PCR to validate RNA-seq expression profiles of nine selected genes that were highly expressed in the spleen and liver, respectively. As shown in Figure 8, despite some quantitative differences at the expression levels between the qRT-PCR and the RNA-seq, the qRT-PCR results revealed a similar expression tendency as the data of transcriptome, confirming the accuracy of the expression profiles in RNA-seq analyses.

\section{DISCUSSION}

Though water environment harbors a mass of pathogens, healthy fish can maintain the balance between host and pathogens by mucosal barrier including digestive enzymes, antimicrobial peptides and immunoglobulins $(36,37)$. In aquaculture, the deterioration of the water environment can lower fish immunity, and this will weaken mucosal barrier of fish and lead to the occurrence of fish diseases. Therefore, it is very essential to study immune-related gene functions and responses of fish against bacterial infection. In mammals, inflammation is a protective response by inducing large amounts of cytokine and complement genes to activate immune cells and eliminate pathogens (28). In fish, so far few research understands the inflammatory mechanisms underlying the bacteria-infection process.

\section{Dynamic Immune Process of Yellow Catfish Against E. ictaluri}

In fish, many studies have been reported recently about transcriptome analysis of the immune response against bacterial infection for a certain tissue or at a certain time point post-infection, but there have been limited researches on the dynamic immune response against bacterial infection in time and space by transcriptome analysis. In this study, we used the RNA-Seq technology to study the dynamic immune response 
A

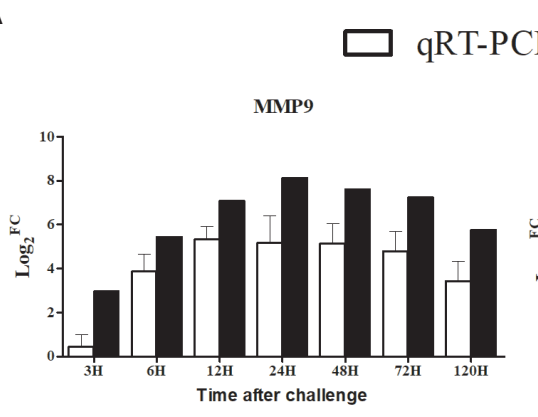

MX3

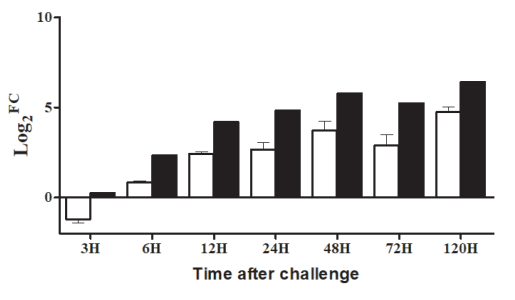

C7

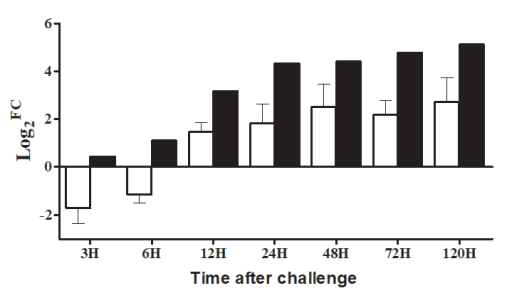

C3

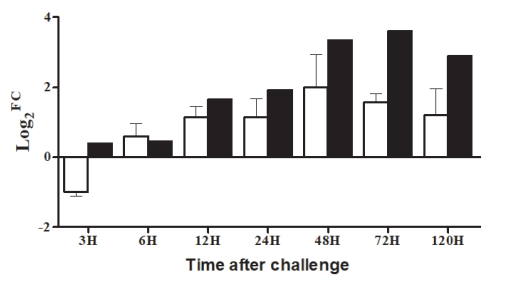

RNA-seq

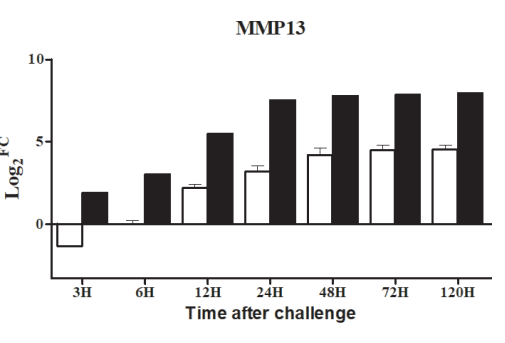

Socs1

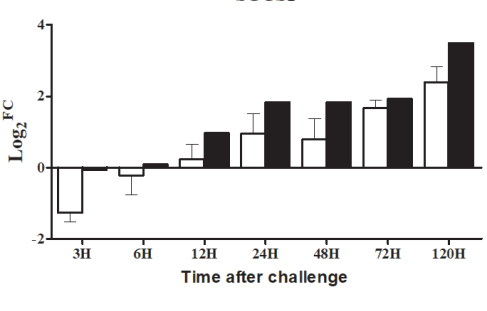

IL-1 $\beta$

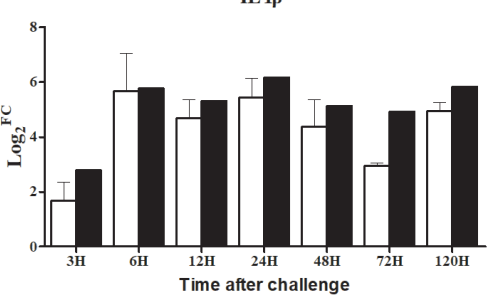

CXCL2

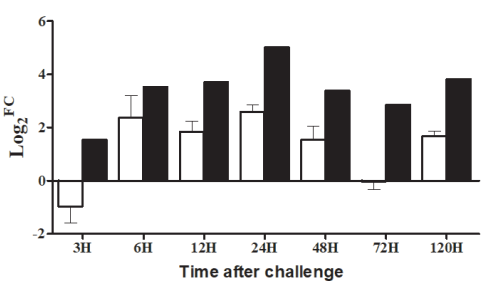

B

$\square$ qRT-PCR $\square$ RNA-seq
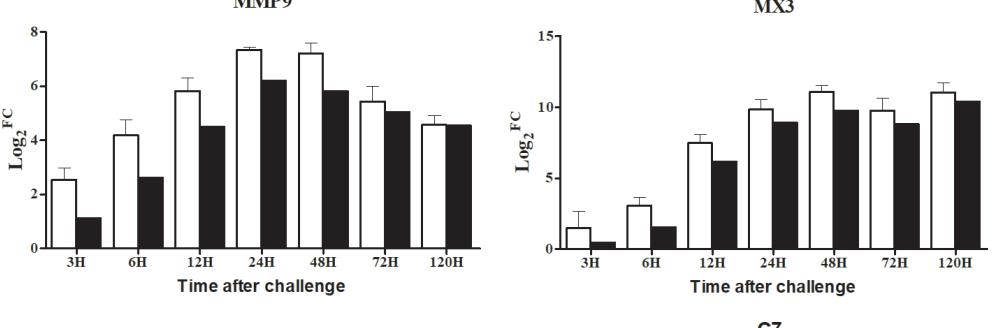

IRF1
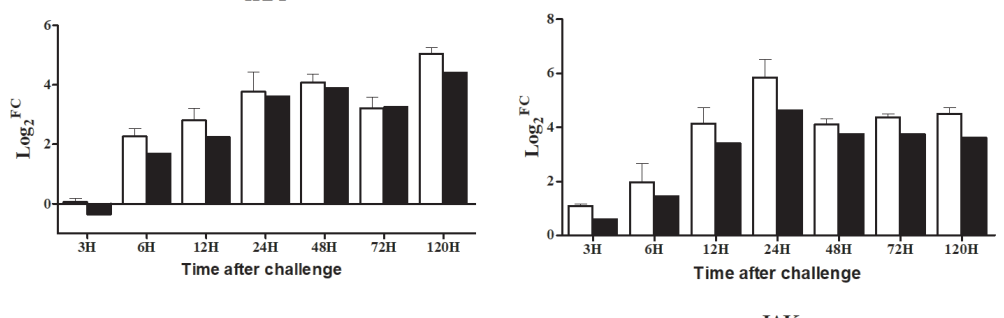

JAK
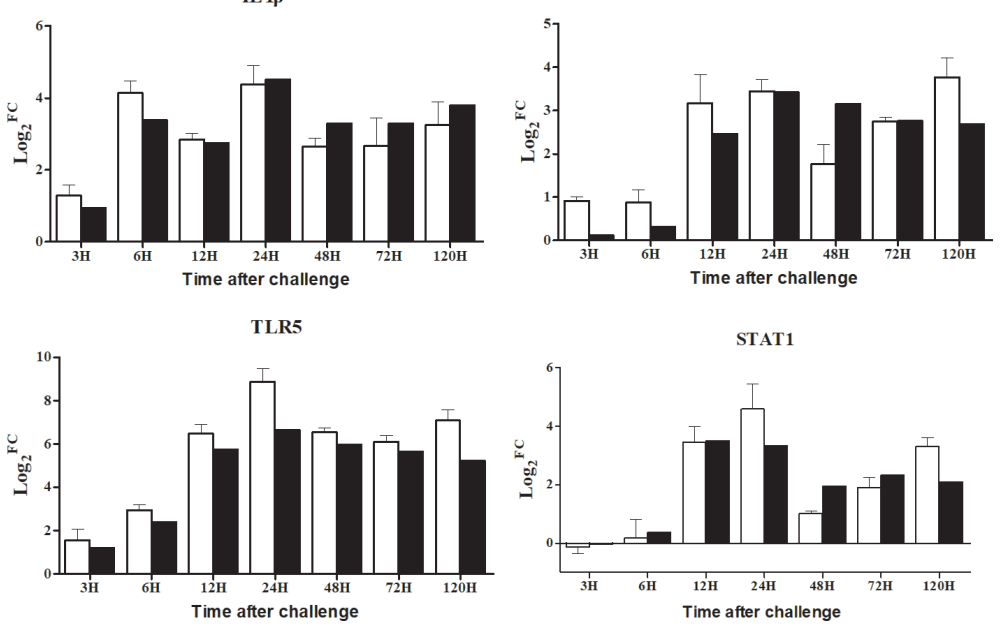

FIGURE 8 | Comparison of the expression profiles of eight DEGs determined by Illumina HiSeq ${ }^{\text {TM }} 2000$ sequencing platform and qRT-PCR at 3 h, 6 h, 12 h, 24 h, 48 h, 72 h, and 120 h post-infection. Data shown are the mean of triplicates \pm SD. (A): Spleen, (B): Liver. 
against E. ictaluri in the spleen and liver of yellow catfish at seven different time points post-infection. Here, we identified a total of 5,540 DEGs in the spleen and 4,161 DEGs in the liver of yellow catfish (Table 4). Overall, the number of annotated DEGs based on the GO database (>60\%) was higher than that from the KEGG database $(\sim 20 \%)$ in the spleen and liver (Table 5), and this difference in yellow catfish was similar to those found in blunt snout bream (14), tilapia (38), topmouth culter (20) and mandarin fish (21). The GO and KEGG enrichment analyses of DEGs at different time points post-infection indicated the variability of biological functions in the spleen and liver of yellow catfish.

In the spleen of yellow catfish, the number of DEGs in the transcriptome was small (156 and 533) at $3 \mathrm{~h}$ and $6 \mathrm{~h}$ postinfection, respectively, subsequently it increased quickly to reach a peak value $(4,260)$ at $72 \mathrm{~h}$. Cytokines are involved in every facet of immunity and inflammation (28). Chemokines are a group of small molecules that can induce chemotaxis in immune cells and regulate the activity of the immune cells through interactions with members of the 7-transmembrane, G-protein-coupled receptor superfamily (39). In the spleen of yellow catfish, cytokines and chemokines associated ontologies were found at 6-120 h, and the cytokine-cytokine receptor interaction (map04060) and the chemokine signaling pathway (map04062) were detected at $12-120 \mathrm{~h}$ in the KEGG enrichment analyses. Gprotein-coupled receptors are the largest family of membrane proteins and mediate most cellular responses to hormones, neurotransmitters, ions, photons and other stimuli (40). In this study, G-protein-coupled-receptor associated GOs were discovered in the spleen at $12 \mathrm{~h}$ and $24 \mathrm{~h}$ in the GO enrichment analyses. These results imply that cytokines and chemokines can be continuously and distinctly transcribed in the spleen of yellow catfish from $6 \mathrm{~h}$ to $120 \mathrm{~h}$ after E. ictaluri infection.

In the liver of yellow catfish, the number of DEGs was also small (399 and 448) at $3 \mathrm{~h}$ and $6 \mathrm{~h}$ post-infection, respectively, but it maintained a high level $(2,908,3,148,3,082$, and 2,998) from $24 \mathrm{~h}$ to $120 \mathrm{~h}$. IL-17 and TNF are strong pro-inflammatory cytokines in mammals $(41,42)$. In the current study, the KEGG enrichment analyses in the liver showed that the IL-17 signaling pathway (map04657), the TNF signaling pathway (map04668) and the Th17 cell differentiation (map04659) were only detected at $6 \mathrm{~h}$ or $12 \mathrm{~h}$, and the complement and coagulation cascades (map04610) enriched the most DEGs at 24-120 h. These results suggest that the immune response in the liver may be activated at $6 \mathrm{~h}$ and $12 \mathrm{~h}$ postinfection by producing cytokines, afterwards the complement system might play a crucial role in immune response from $24 \mathrm{~h}$ to $120 \mathrm{~h}$ in the liver. During human infection, food intake will decrease with a change in leptin synthesis, and this will probably reduce the ingestion of other pathogens, activate energy-requiring mechanisms and diminish the competition of epitopes from nutrients for crucial receptors for pathogen sensing (43). In the liver of yellow catfish, metabolic and reproductive process associated GOs were detected at $12-120 \mathrm{~h}$ in the GO enrichment analyses, the fat digestion and absorption (map04975) was found at 12-120 h, the PPAR signaling pathway (map03320) and the glycerolipid metabolism (map00561) were found at 24-72 $\mathrm{h}$ in the KEGG enrichment analyses, indicating that the metabolic regulation in the liver can be activated at about $12 \mathrm{~h}$ post-infection to provide energy for yellow catfish against bacterial infection.

\section{Expression Changes and Potential Roles of Inflammation-Related DEGs Against E. ictaluri}

To better understand the inflammation response of yellow catfish against bacterial infection, a graphic overview of its inflammation response was drawn based on the transcriptome analysis (Figure 9). The pattern-recognition receptors can recognize specific components of microorganisms and trigger inflammatory responses, thus eliminate the invading microorganisms (44). In mammals, TLR5 recognizes the flagellin of bacterial flagella through MYD88 signaling (45), and NOD1 sense bacterial PGN fragments by RIPK2 signaling (46). In fish, two tlr5 genes (tlr5M and th5S) and nod1 mRNAs were up-regulated notably after bacterial infection $(47,48)$. In Japanese flounder, tlr5 can induce the expression of interleukin- $1 \beta$ and NF- $\kappa B$ genes (49). In yellow catfish, both trim and nod 1 mRNAs were induced notably and continuously in the liver from $6 \mathrm{~h}$ or $12 \mathrm{~h}$ to $120 \mathrm{~h}$ post-infection, and the predicted protein structures of two genes were similar to those of mammals. In mammals, NLRP3 can induce proinflammatory cytokines through recruiting apoptosis-associated speck-like protein (ASC) and Caspase-1 and constituting a multiprotein inflammasome complex (46). Japanese flounder nlrp3 mRNA is significantly up-regulated after bacterial infection (50). In yellow catfish, two nlrp3 genes (nlrp3-1 and nlrp3-2) were distinctly induced at $120 \mathrm{~h}$ and at $24-120 \mathrm{~h}$, respectively. Moreover, compared with human NLRP3, two nlrp3 genes of yellow catfish lacked a PYRIN domain with important roles in binding to ASC (46), therefore it is necessary to further verify the function of yellow catfish nlrp3s in the future.

Once inflammatory processes are triggered, large amounts of pro-inflammatory cytokines are activated and released (28). In mammals, IL-1 $\beta$ and TNF, as symbolic pro-inflammation cytokines, can activate macrophages and neutrophils directly, and CSF-1 and IL-34 can drive monocyte differentiation into macrophages $(41,51,52)$. IL- 12 can promote the differentiation of type 1 helper T cells (Th1) (53). IFN- $\gamma$, derived from Th 1 cells, can activate neutrophils (28). IL-17A and IL-17 F, derived mainly from Th17 cells, can induce the expressions of inflammatory cytokines, chemokines and antibacterial peptides (42). In fishes, multiple homologous genes of il-1 $\beta$, TNF $\alpha$, il-6, il-11, il-12 $\alpha$, il-17a/f and ifn- $\gamma$ have been identified due to several whole-genome duplications in fish evolution, and they have similar bioactivity to those of mammals (54-58). In this study, yellow catfish il-1 $\beta$, tnf $\alpha$, tnf6, il-6, il-11, il-12 $\alpha$, il-17a/f1, and ifn- $\gamma$ mRNAs were up-regulated significantly and continuously, while csf- 1 and il-34 mRNAs were distinctly induced at late time points after E. ictaluri infection. Moreover, the predicted protein structures of these inflammatory cytokines contained their characteristic family domains. These results imply that yellow catfish immune cells can be activated quickly to eliminate invading pathogens.

In mammals, IL- $1 \beta$ can bind to IL-1R1 to activate MyD88 signaling, and IL-1R2 lacking the TIR domain can bind 




fraudulently to IL-1 $\beta$ and prevent signal transduction (59). TNF $\alpha$ can bind to TNFR1 and TNFR2 to activate TRADD signaling by a cytoplasmic DEATH domain (41). IFN- $\gamma$ can activate the JAK-STAT signal pathway through IFN- $\gamma$ R1 and IFN- $\gamma$ R2 (60). In various fishes, il-1r1, il-1r2, tnfr1, tnfr2, ifn $\gamma \mathrm{r} 1$ and ifn $\gamma \mathrm{r} 2$ have been identified, and their mRNAs are notably induced after bacteria or LPS stimulation (60-64). In yellow catfish, il-1r1 and tnfr1 mRNAs were significantly up-regulated at $6-120 \mathrm{~h}$ post-infection, and ifn $\gamma \mathrm{r} 1 \mathrm{mRNA}$ was notably induced at $48 \mathrm{~h}, 72 \mathrm{~h}$, and $120 \mathrm{~h}$, whereas il-1r2 mRNA was distinctly induced only at $3 \mathrm{~h}$. Similar to mammals, yellow catfish il-1rs possess characteristic IG domains in the extracellular region and a cytoplasmic TIR domain except that il-1r2 lacks the TIR domain for signaling, and yellow catfish tnfr1 also contain a DEATH domain. In mammals, IL-6R $\beta$ is a shared receptor in the IL- 6 family, and IL- 6 and IL- 11 also need to bind to IL-6R $\alpha$ and IL-11R, respectively, to activate the JAK-STAT signal pathway (65). IL-12 $\alpha$ can bind to IL-12/IL-23 $\beta$, and then combine with 
IL-12R $\beta 1$ and IL-12R $\beta 2$ to activate the JAK-STAT signal pathway (53). So far, little is known about fish il-6ro, il-6r $\beta$ and il-12r $\beta$. Rainbow trout il-6ro and il-6r $\beta$ have been identified and their mRNAs are up-regulated after stimulation with LPS and poly I:C (66). In this study, yellow catfish il-6ro and il-6r $\beta$ mRNAs were significantly up-regulated from $3 \mathrm{~h}$ or $12 \mathrm{~h}$ to $120 \mathrm{~h}$ post-infection. Yellow catfish il-12r $\beta$ possesses four fibronectin type III domains, while its mRNA was notably down-regulated at $48 \mathrm{~h}, 72 \mathrm{~h}$, and $120 \mathrm{~h}$. These results reveal that compared with mammals, inflammatory cytokine receptors in fish have similar protein structure and expression changes after bacterial infection, and the signal pathways of these inflammatory cytokines are conserved.

Chemokines play a crucial role in inflammation and immunity (39). In humans, 44 chemokines and 23 chemokine receptors have been identified (67). In teleosts, the family of chemokine is more complex than that in mammals. More than 100 different chemokines have been found in zebrafish (68). Only a few orthologues of mammalian chemokines have been identified in fish, such as cxcl8, cxcl11, cxcl12, ccl19 and $\operatorname{ccl} 20$. There is a limited understanding of the bioactivity of fish chemokines in the immune response. In mammals, CXCL1CXCL3 and CXCL5-CXCL8 have the conserved "ELR" motif, and they are chemotactic factors for neutrophils, while CXCL9CXCL12 lacking "ELR" motif can recruit and activate lymphocytes T and NK cells (69). Mammalian CC chemokines are chemoattractant for macrophages and neutrophils (70). In this study, yellow catfish cxcls and ccls also have a typical C-X-C and $\mathrm{C}-\mathrm{C}$ structure as mammals, respectively. Moreover, cxcl1, cxcl2, cxcl9, cxcl11.1, cxcl11.6-1, cxcl11.6-2, cxcl12, ccl3-2, ccl191, ccl19-2, ccl20, and cclSCYA 101, 107, 114 mRNAs were significantly and continuously induced after E. ictaluri infection, implying that yellow catfish immune cells can be activated and recruited to the sites of infection at early time points post-infection. In mammals, chemokine signals are transduced through binding to members of the seventransmembrane, G-protein-coupled receptor superfamily (29). In yellow catfish, multiple genes of cxcrs and ccrs were detected to have a seven-transmembrane domain. Furthermore, cxcr1, cxcr3-2, ccr3, and ccr5 mRNAs were notably up-regulated at $6 \mathrm{~h}$ or $12 \mathrm{~h}$ and maintained until $120 \mathrm{~h}$ post-infection, whereas cxcr3-1, cxcr4, ccr4, ccr7, and ccr9 mRNAs were notably downregulated after $E$. ictaluri infection, therefore it is necessary to further verify the bioactivity of these chemokine receptors of yellow catfish in the following study. Besides, CCL14 and CCL18 can inhibit the pro-inflammatory immune response $(71,72)$. Similarly, yellow catfish ccl14 and ccl18 mRNAs were down-regulated after E. ictaluri infection, suggesting that the ccl14 and ccl18 may play crucial anti-inflammation roles in fish.

Complement has been viewed as a supportive "first line of defense" against microbial intruders, and can quickly tag and eliminate them (73). A variety of complement genes have been identified in fish (74), but the function and signaling pathway of fish complement are not clear. There are three complement pathways in mammals: classical, alternative and lectin (73). The classical pathway is activated by $\mathrm{C} 1$ family $(\mathrm{Clq}, \mathrm{C} 1 \mathrm{r}$, and $\mathrm{C} 1 \mathrm{~s}$ ) cleaving $\mathrm{C} 4$ and $\mathrm{C} 2$. In contrast, the lectin pathway is activated through mannose-binding lectin (MBL) and MASPs cleaving both C4 and C2 (73). After E. ictaluri infection in yellow catfish, three $\mathrm{C} 1 \mathrm{q}$ genes (c1q-1, clq-2, and clq-3) with a C1Q domain were detected and only c1q-2 was notably induced in the liver, whereas $\mathrm{c} 1 \mathrm{r}$ and $\mathrm{cls}$ were notably down-regulated in the liver. Yellow catfish mbl was not detected and two masp genes (masp1 and masp2) were notably down-regulated in the liver after bacterial infection. Yellow catfish c2 was not detected, and c4 was distinctly induced in the spleen and liver after bacterial infection. Similar to mammals, two masp genes of yellow catfish share structural similarity with $\mathrm{clr}$ and $\mathrm{cls}$. In the alternative pathway of mammals, C3 is cleaved by the factor B (FB) and factor D (FD) to activate complement (73). In yellow catfish, two c3 genes were detected to be induced significantly after E. ictaluri infection. Meanwhile, $\mathrm{cfb}$ was notably down-regulated, whereas two $\mathrm{cfb} / \mathrm{c}$ genes (cfb/c-1 and $\mathrm{cfb} / \mathrm{c}-2)$ with similar protein structure to $\mathrm{cfb}$ were significantly up-regulated, so did cfd gene. These results imply that yellow catfish has complement activation pathways similar to mammals, the alternative pathway of yellow catfish may be activated after E. ictaluri infection, but the classical and lectin pathways may be suppressed. While the complement pathways are activated, C5 is cleaved to the anaphylatoxin C5a and fragment C5b, and then C5b, C6, C7, C8 and C9 can form MAC to eliminate pathogen (73). In yellow catfish, c5-c9 mRNAs had high expression levels in the spleen or liver, and c6-c9 contained a MAC domain, implying that they might play potential roles in the immune responses of yellow catfish against pathogens.

In mammals, MyD88 is an important adaptor molecule involved in the IL-1/TLR signaling pathway (51). TRADD, as an important adaptor molecule of TNF signal pathway, can combine with TNFR to activate the downstream signaling (41). NOD1 and NOD2 can activate NF- $\kappa B$ pathway through CARD domain recruiting adaptor molecule RIPK-2 (75). ACT1 can bind to IL-17R to modulate IL-17 signaling (42). In various fish, myd88 has been detected to have high transcripts levels after pathogens infection, while little is known for fish tradd, ripk-2 and act1 genes. In this study, yellow catfish myd88, tradd, ripk-2, and act1 mRNAs were significantly induced after E. ictaluri infection, and four genes possessed similar protein structures to those of mammals. In mammals, seven TRAF proteins have emerged as adapter proteins to control the signal transduction of IL-1, IL-17, and TLR family (76). TRAF proteins consist of a unique and highly conserved MATH domain, but the C-terminus of TRAF7 is replaced by seven WD40 repeats (76). In teleosts, little is known about the traf gene family except that fish traf6 might be involved in the innate immune response (77). In the present study, yellow catfish traf1, 2, 5 and 7 were detected to have conserved protein structures, and traf1, 2 and 7 mRNAs were notably up-regulated after E. ictaluri infection. In mammals, IRAK proteins are an important class of kinases involved in the IL-1/TLR signaling pathway, and all four IRAKs have similar protein architectures: an $\mathrm{N}$-terminal death domain and a kinase domain (78). So far there are few studies on IRAKs from teleosts. Recently, some reports suggest that fish IRAK4 could suppress MyD88-dependent NF-kB 
activation $(77,79)$. In this study, yellow catfish irak1, 3 , and 4 mRNAs were distinctly induced after E. ictaluri infection and the three iraks genes had a death domain and a kinase domain as mammals. These results exhibit that these adaptor molecules have conserved protein structures, but their bioactivity need to further be explored in fish.

In conclusion, this study showed the transcriptomic profiles of yellow catfish in the spleen and liver at $3 \mathrm{~h}, 6 \mathrm{~h}, 12 \mathrm{~h}, 24 \mathrm{~h}, 48$ $\mathrm{h}, 72 \mathrm{~h}$, and $120 \mathrm{~h}$ after E. ictaluri infection, evidencing that an extensive transcriptional change was elicited at $12-120 \mathrm{~h}$ postinfection in the spleen and liver. Subsequently, the GO and KEGG enrichment analyses of DEGs were performed to uncover the dynamic immune responses of yellow catfish in the spleen and liver at different time points post-infection. On the whole, inflammatory cytokines and chemokines mRNAs were quickly and distinctly up-regulated at early time points ( 3 or $6 \mathrm{~h}$ ) postinfection, then complement component mRNAs were induced continuously and notably from 12 or $24 \mathrm{~h}$. In terms of mRNA tissue expressions, inflammatory cytokines and chemokines were mainly produced in the spleen, while more complement genes were induced in the liver after E. ictaluri infection. Finally, the inflammation response of yellow catfish was graphically overviewed and discussed, including pattern-recognition receptors, inflammatory cytokines, chemokines, complements and inflammation-related signal pathways. Overall, the transcriptomic data and relevant analyses will help to better understand the molecular defense mechanisms against bacterial infection, and will provide basic information to further study the immune regulation of bacterial diseases in yellow catfish.

\section{DATA AVAILABILITY STATEMENT}

The datasets presented in this study can be found in online repositories. The transcriptome data have been deposited to NCBI

\section{REFERENCES}

1. Qian X, Ba Y, Zhuang Q, Zhong G. RNA-Seq technology and its application in fish transcriptomics. OMICS (2014) 18:98-110. doi: 10.1089/ omi.2013.0110

2. Costa V, Angelini C, De Feis I, Ciccodicola A. Uncovering the complexity of transcriptomes with RNA-Seq. J BioMed Biotechnol (2010) 2010:853-916. doi: $10.1155 / 2010 / 853916$

3. Chu Q, Song W, Cui J, Xu T. Genome-guided transcriptome analysis of miiuy croaker provides insights into pattern recognition receptors and cytokines in response to Vibrio anguillarum. Dev Comp Immunol (2017) 73:72-8. doi: 10.1016/j.dci.2017.03.009

4. Dang Y, Xu X, Shen Y, Hu M, Zhang M, Li L, et al. Transcriptome analysis of the innate immunity-related complement system in spleen tissue of Ctenopharyngodon idella infected with Aeromonas hydrophila. PloS One (2016) 11:e0157413. doi: 10.1371/journal.pone.0157413

5. Gao C, Fu Q, Su B, Zhou S, Liu F, Song L, et al. Transcriptomic profiling revealed the signatures of intestinal barrier alteration and pathogen entry in turbot (Scophthalmus maximus) following Vibrio anguillarum challenge. Dev Comp Immunol (2016) 65:159-68. doi: 10.1016/j.dci.2016.07.007

6. Kumar R, Sahoo PK, Barat A. Transcriptome profiling and expression analysis of immune responsive genes in the liver of golden mahseer (Tor putitora) challenged with Aeromonas hydrophila. Fish Shellish Immunol (2017) 67:655-66. doi: 10.1016/j.fsi.2017.06.053
(BioProject ID: PRJNA690649), and the accession numbers are SRR13385414 to SRR13385461.

\section{ETHICS STATEMENT}

The animal study was reviewed and approved by Institutional Animal Care and Use Committees (IACUC) of HZAU, Wuhan, P. R. China.

\section{AUTHOR CONTRIBUTIONS}

$\mathrm{XZ}$ performed the experiments, analyzed the data, and wrote the manuscript. XZ, G-RZ, WJ, X-FM, Z-LL and K-JW conceived and designed the study. Z-CS helped with the preparation of experimental fishes. XZ, Z-LL and K-JW revised the manuscript. All authors contributed to the article and approved the submitted version.

\section{FUNDING}

This study was supported by the Biodiversity Survey and Assessment Project of the Ministry of Ecology and Environment, China (Grant No. 2019HJ2096001006), and the National Natural Science Foundation of China (Grant No. 31772851).

\section{SUPPLEMENTARY MATERIAL}

The Supplementary Material for this article can be found online at: https://www.frontiersin.org/articles/10.3389/fimmu.2021. 625928/full\#supplementary-material

7. Li Z, Liu X, Cheng J, He Y, Wang X, Wang Z, et al. Transcriptome profiling provides gene resources for understanding gill immune responses in Japanese flounder (Paralichthys olivaceus) challenged with Edwardsiella tarda. Fish Shellfish Immunol (2018) 72:593-603. doi: 10.1016/j.fsi.2017.11.041

8. Liu X, Li Z, Wu W, Liu Y, Liu J, He Y, et al. Sequencing-based network analysis provides a core set of gene resource for understanding kidney immune response against Edwardsiella tarda infection in Japanese flounder. Fish Shellfish Immunol (2017) 67:643-54. doi: 10.1016/j.fsi.2017.06.051

9. Long M, Zhao J, Li T, Tafalla C, Zhang Q, Wang X, et al. Transcriptomic and proteomic analyses of splenic immune mechanisms of rainbow trout (Oncorhynchus mykiss) infected by Aeromonas salmonicida subsp. salmonicida. J Proteomics (2015) 122:41-54. doi: 10.1016/j.jprot.2015.03.031

10. Ordas A, Hegedus Z, Henkel CV, Stockhammer OW, Butler D, Jansen HJ, et al. Deep sequencing of the innate immune transcriptomic response of zebrafish embryos to Salmonella infection. Fish Shellfish Immunol (2011) 31:716-24. doi: 10.1016/j.fsi.2010.08.022

11. Peatman E, Li C, Peterson BC, Straus DL, Farmer BD, Beck BH. Basal polarization of the mucosal compartment in Flavobacterium columnare susceptible and resistant channel catfish (Ictalurus punctatus). Mol Immunol (2013) 56:317-27. doi: 10.1016/j.molimm.2013.04.014

12. Qin C, Gong Q, Wen Z, Yuan D, Shao T, Wang J, et al. Transcriptome analysis of the spleen of the darkbarbel catfish Pelteobagrus vachellii in response to Aeromonas hydrophila infection. Fish Shellfish Immunol (2017) 70:498-506. doi: $10.1016 /$ j.fsi.2017.09.042 
13. Rebl A, Korytar T, Kobis JM, Verleih M, Krasnov A, Jaros J, et al. Transcriptome profiling reveals insight into distinct immune responses to Aeromonas salmonicida in gill of two rainbow trout strains. Mar Biotechnol (NY) (2014) 16:333-48. doi: 10.1007/s10126-013-9552-x

14. Tran NT, Gao ZX, Zhao HH, Yi SK, Chen BX, Zhao YH, et al. Transcriptome analysis and microsatellite discovery in the blunt snout bream (Megalobrama amblycephala) after challenge with Aeromonas hydrophila. Fish Shellfish Immunol (2015) 45:72-82. doi: 10.1016/j.fsi.2015.01.034

15. Valenzuela-Miranda D, Gallardo-Escarate C. Novel insights into the response of Atlantic salmon (Salmo salar) to Piscirickettsia salmonis: Interplay of coding genes and lncRNAs during bacterial infection. Fish Shellfish Immunol (2016) 59:427-38. doi: 10.1016/j.fsi.2016.11.001

16. Wang YD, Wang YH, Hui CF, Chen JY. Transcriptome analysis of the effect of Vibrio alginolyticus infection on the innate immunity-related TLR5-mediated induction of cytokines in Epinephelus lanceolatus. Fish Shellfish Immunol (2016) 52:31-43. doi: 10.1016/j.fsi.2016.03.013

17. Yang Y, Yu H, Li H, Wang A. Transcriptome profiling of grass carp (Ctenopharyngodon idellus) infected with Aeromonas hydrophila. Fish Shellfish Immunol (2016) 51:329-36. doi: 10.1016/j.fsi.2016.02.035

18. Zhang X, Wang S, Chen S, Chen Y, Liu Y, Shao C, et al. Transcriptome analysis revealed changes of multiple genes involved in immunity in Cynoglossus semilaevis during Vibrio anguillarum infection. Fish Shellfish Immunol (2015) 43:209-18. doi: 10.1016/j.fsi.2014.11.018

19. Zhao C, Fu M, Wang C, Jiao Z, Qiu L. RNA-Seq analysis of immune-relevant genes in Lateolabrax japonicus during Vibrio anguillarum infection. Fish Shellfish Immunol (2016) 52:57-64. doi: 10.1016/j.fsi.2016.02.032

20. Zhao L, Tu J, Zhang Y, Wang J, Yang L, Wang W, et al. Transcriptomic analysis of the head kidney of topmouth culter (Culter alburnus) infected with Flavobacterium columnare with an emphasis on phagosome pathway. Fish Shellfish Immunol (2016) 57:413-8. doi: 10.1016/j.fsi.2016.09.001

21. Zhou W, Zhang Y, Wen Y, Ji W, Zhou Y, Ji Y, et al. Analysis of the transcriptomic profilings of mandarin fish (Siniperca chuatsi) infected with Flavobacterium columnare with an emphasis on immune responses. Fish Shellfish Immunol (2015) 43:111-9. doi: 10.1016/j.fsi.2014.12.006

22. Zhu R, Liu XX, Lv X, Li SY, Li YD, Yu XJ, et al. Deciphering transcriptome profile of the yellow catfish (Pelteobagrus fulvidraco) in response to Edwardsiella ictaluri. Fish Shellfish Immunol (2017) 70:593-608. doi: 10.1016/j.fsi.2017.08.040

23. Maekawa S, Wang PC, Chen SC. Comparative study of immune reaction against bacterial infection from transcriptome analysis. Front Immunol (2019) 10:153. doi: 10.3389/fimmu.2019.00153

24. Yang R, Xie C, Fan Q, Gao C, Fang L. Ontogeny of the digestive tract in yellow catfish Pelteobagrus fulvidraco larvae. Aquaculture (2010) 302:112-23. doi: 10.1016/j.aquaculture.2010.02.020

25. Ye S, Li H, Qiao G, Li Z. First case of Edwardsiella ictaluri infection in China farmed yellow catfish Pelteobagrus fulvidraco. Aquaculture (2009) 292:6-10. doi: 10.1016/j.aquaculture.2009.03.036

26. Liu JY, Li AH, Zhou DR, Wen ZR, Ye XP. Isolation and characterization of Edwardsiella ictaluri strains as pathogens from diseased yellow catfish Pelteobagrus fulvidraco (Richardson) cultured in China. Aquacult Res (2010) 41:1835-44. doi: 10.1111/j.1365-2109.2010.02571.x

27. Hawke JP, McWhorter AC, Steigerwalt AG, Brenner DJ. Edwardsiella ictaluri sp. nov., the causative agent of enteric septicemia of catfish. Int J Syst Bacterio (1981) 31:396-400. doi: 10.1099/00207713-31-4-396

28. Netea MG, Balkwill F, Chonchol M, Cominelli F, Donath MY, GiamarellosBourboulis EJ, et al. A guiding map for inflammation. Nat Immunol (2017) 18:826-31. doi: 10.1038/ni.3790

29. Federica Sallusto MB. Chemokines and leukocyte traffic. Nat Immunol (2008) 9:949-52. doi: 10.1038/ni.f.214/nature

30. Zou M, Zhang X, Shi Z, Lin L, Ouyang G, Zhang G, et al. and Ji W. A Comparative transcriptome analysis between wild and albino yellow catfish (Pelteobagrus fulvidraco). PloS One (2015) 10:e0131504. doi: 10.1371/ journal.pone.0131504

31. Liu QN, Xin ZZ, Liu Y, Zhang DZ, Jiang SH, Chai XY, et al. De novo transcriptome assembly and analysis of differential gene expression following lipopolysaccharide challenge in Pelteobagrus fulvidraco. Fish Shellfish Immunol (2018) 73:84-91. doi: 10.1016/j.fsi.2017.11.045

32. Liu Y, Xin ZZ, Zhang DZ, Wang ZF, Zhu XY, Tang BP, et al. Transcriptome analysis of yellow catfish (Pelteobagrus fulvidraco) liver challenged with polyriboinosinic polyribocytidylic acid (poly I:C). Fish Shellfish Immunol (2017) 68:395-403. doi: 10.1016/j.fsi.2017.07.030

33. Ye H, Xiao S, Wang X, Wang Z, Zhang Z, Zhu C, et al. Characterization of spleen transcriptome of Schizothorax prenanti during Aeromonas hydrophila infection. Mar Biotechnol (NY) (2018) 20:246-56. doi: 10.1007/s10126-0189801-0

34. Causey DR, Pohl MAN, Stead DA, Martin SAM, Secombes CJ, Macqueen DJ. High-throughput proteomic profiling of the fish liver following bacterial infection. BMC Genomics (2018) 19:719. doi: 10.1186/s12864-018-5092-0

35. Livak KJ, Schmittgen TD. Analysis of relative gene expression data using realtime quantitative PCR and the 2(-Delta Delta C(T)) Method. Methods (2001) 25:402-8. doi: 10.1006/meth.2001.1262

36. Salinas I. The Mucosal Immune System of Teleost Fish. Biol (Basel) (2015) 4:525-39. doi: 10.3390/biology4030525

37. Ribet D, Cossart P. How bacterial pathogens colonize their hosts and invade deeper tissues. Microbes Infect (2015) 17:173-83. doi: 10.1016/j.micinf.2015.01.004

38. Zhu J, Li C, Ao Q, Tan Y, Luo Y, Guo Y, et al. Trancriptomic profiling revealed the signatures of acute immune response in tilapia (Oreochromis niloticus) following Streptococcus iniae challenge. Fish Shellfish Immunol (2015) 46:346-53. doi: 10.1016/j.fsi.2015.06.027

39. Thelen M. Dancing to the tune of chemokines. Nat Immunol (2001) 2:129-34. doi: $10.1038 / 84224$

40. Rosenbaum DM, Rasmussen SG, Kobilka BK. The structure and function of G-protein-coupled receptors. Nature (2009) 459:356-63. doi: 10.1038/ nature 08144

41. Dostert C, Grusdat M, Letellier E, Brenner D. The TNF family of ligands and receptors: communication modules in the immune system and beyond. Physiol Rev (2019) 99:115-60. doi: 10.1152/physrev.00045.2017

42. Gu C, Wu L, Li X. IL-17 family: cytokines, receptors and signaling. Cytokine (2013) 64:477-85. doi: 10.1016/j.cyto.2013.07.022

43. Franceschi C, Garagnani P, Parini P, Giuliani C, Santoro A. Inflammaging: a new immune-metabolic viewpoint for age-related diseases. Nat Rev Endocrinol (2018) 14:576-90. doi: 10.1038/s41574-018-0059-4

44. Cao X. Self-regulation and cross-regulation of pattern-recognition receptor signalling in health and disease. Nat Rev Immunol (2016) 16:35-50. doi: $10.1038 /$ nri.2015.8

45. Kawai T, Akira S. The role of pattern-recognition receptors in innate immunity: update on Toll-like receptors. Nat Immunol (2010) 11:373-84. doi: 10.1038/ni.1863

46. Le HT, Harton JA. Pyrin- and CARD-only proteins as regulators of NLR functions. Front Immunol (2013) 4:275. doi: 10.3389/fimmu.2013.00275

47. Gu T, Lu L, Wang J, Tian L, Wei W, Wu X, et al. The NOD1 and NOD2 in mandarin fish (Siniperca chuatsi): molecular characterization, tissue distribution, and expression analysis. BMC Genet (2018) 19:61. doi: 10.1186/s12863-018-0667-y

48. Du X, Li D, Li Y, Wu J, Huang A, Bu G, et al. Clone, identification and functional character of two toll-like receptor 5 molecules in Schizothorax prenanti. Fish Shellfish Immunol (2019) 95:81-92. doi: 10.1016/j.fsi.2019.10.027

49. Zhang L, Gao Z, Yu L, Zhang B, Wang J, Zhou J. Nucleotide-binding and oligomerization domain (NOD)-like receptors in teleost fish: Current knowledge and future perspectives. J Fish Dis (2018) 41:1317-30. doi: $10.1111 /$ jfd.12841

50. Chen H, Ding S, Tan J, Yang D, Zhang Y, Liu Q. Characterization of the Japanese flounder NLRP3 inflammasome in restricting Edwardsiella piscicida colonization in vivo. Fish Shellfish Immunol (2020) 103:169-80. doi: 10.1016/ j.fsi.2020.04.063

51. Dinarello CA. Overview of the IL-1 family in innate inflammation and acquired immunity. Immunol Rev (2018) 281:8-27. doi: 10.1111/imr.12621

52. Grayfer L, Kerimoglu B, Yaparla A, Hodgkinson JW, Xie J, Belosevic M. Mechanisms of fish macrophage antimicrobial immunity. Front Immunol (2018) 9:1105:1105. doi: 10.3389/fimmu.2018.01105

53. Chyuan IT, Lai JH. New insights into the IL-12 and IL-23: From a molecular basis to clinical application in immune-mediated inflammation and cancers. Biochem Pharmacol (2020) 175:113928. doi: 10.1016/j.bcp.2020.113928

54. Hong S, Li R, Xu Q, Secombes CJ, Wang T. Two types of TNF-alpha exist in teleost fish: phylogeny, expression, and bioactivity analysis of type-II TNFalpha3 in rainbow trout Oncorhynchus mykiss. J Immunol (2013) 191:595972. doi: 10.4049/jimmunol.1301584 
55. Husain M, Bird S, van Zwieten R, Secombes CJ, Wang T. Cloning of the IL1beta3 gene and IL-1beta4 pseudogene in salmonids uncovers a second type of IL-1beta gene in teleost fish. Dev Comp Immunol (2012) 38:431-46. doi: 10.1016/j.dci.2012.07.010

56. Ding Y, Ao J, Ai C, Chen X. Molecular and functional identification of three interleukin-17A/F (IL-17A/F) homologues in large yellow croaker (Larimichthys crocea). Dev Comp Immunol (2016) 55:221-32. doi: 10.1016/j.dci.2015.09.010

57. Zhu Q, Fan ZJ, Cai SX, Yao CL. Molecular and immunological characterizations of interleukin-11 in large yellow croaker (Larimichthys crocea). Fish Shellfish Immunol (2020) 100:9-17. doi: 10.1016/j.fsi.2020.02.065

58. Zou J, Secombes CJ. The function of fish cytokines. Biol (Basel) (2016) 5:23. doi: 10.3390/biology5020023

59. Mantovani A, Dinarello CA, Molgora M, Garlanda C. Interleukin-1 and related cytokines in the regulation of inflammation and immunity. Immunity (2019) 50:778-95. doi: 10.1016/j.immuni.2019.03.012

60. Kim JW, Kwon MG, Park MA, Hwang JY, Baeck GW, Park CI. Molecular identification and expression analysis of a novel tumor necrosis factor receptor from the black rockfish, Sebastes schlegelii. Dev Comp Immunol (2011) 35:258-62. doi: 10.1016/j.dci.2010.11.004

61. Eggestol HO, Lunde HS, Knutsen TM, Haugland GT. Interleukin-1 ligands and receptors in lumpfish (Cyclopterus lumpus L.): molecular characterization, phylogeny, gene expression, and transcriptome analyses. Front Immunol (2020) 11:502. doi: 10.3389/fimmu.2020.00502

62. Gao J, Jiang X, Wang J, Xue Y, Li X, Sun Z, et al. Phylogeny and expression modulation of interleukin 1 receptors in grass carp (Ctenopharyngodon idella). Dev Comp Immunol (2019) 99:103401. doi: 10.1016/j.dci.2019.103401

63. Zhang S, Wang X, Li C, Feng S, Zhang A, Yang K, et al. Identification and functional characterization of grass carp (Ctenopharyngodon idella) tumor necrosis factor receptor 2 and its soluble form with potentiality for targeting inflammation. Fish Shellfish Immunol (2019) 86:393-402. doi: 10.1016/ j.fsi.2018.11.061

64. Gan Z, Chen SN, Huang B, Zou J, Nie P, Fish type I. and type II interferons: composition, receptor usage, production and function. Rev Aquacult (2019) 12:773-804. doi: 10.1111/raq.12349

65. Jones SA, Jenkins BJ. Recent insights into targeting the IL-6 cytokine family in inflammatory diseases and cancer. Nat Rev Immunol (2018) 18:773-89. doi: 10.1038/s41577-018-0066-7

66. Costa MM, Wang T, Monte MM, Secombes CJ. Molecular characterization and expression analysis of the putative interleukin 6 receptor (IL-6Ralpha and glycoprotein-130) in rainbow trout (Oncorhynchus mykiss): salmonid IL6Ralpha possesses a polymorphic N-terminal Ig domain with variable numbers of two repeats. Immunogenetics (2012) 64:229-44. doi: 10.1007/ s00251-011-0581-1

67. Turner MD, Nedjai B, Hurst T, Pennington DJ. Cytokines and chemokines: At the crossroads of cell signalling and inflammatory disease. Biochim Biophys Acta (2014) 1843:2563-82. doi: 10.1016/j.bbamcr.2014.05.014

68. Alejo A, Tafalla C. Chemokines in teleost fish species. Dev Comp Immunol (2011) 35:1215-22. doi: 10.1016/j.dci.2011.03.011
69. Groblewska M, Litman-Zawadzka A, Mroczko B. The role of selected chemokines and their receptors in the Development of Gliomas. Int J Mol Sci (2020) 21:3704. doi: 10.3390/ijms21103704

70. Mirabelli-Badenier M, Braunersreuther V, Viviani GL, Dallegri F, Quercioli A, Veneselli E, et al. CC and CXC chemokines are pivotal mediators of cerebral injury in ischaemic stroke. Thromb Haemost (2011) 105:409-20. doi: 10.1160/ TH10-10-0662

71. Cui LY, Chu SF, Chen NH. The role of chemokines and chemokine receptors in multiple sclerosis. Int Immunopharmacol (2020) 83:106314. doi: 10.1016/ j.intimp.2020.106314

72. Gupta S, Fuchs B, Schulz-Maronde S, Heitland A, Escher SE, Münch J, et al. Inhibition of airway inflammation and HIV entry by NNY-CCL14 treatment: role of CCR1 and CCR5. J Allergy Clin Immunol (2007) 119:139. doi: 10.1016/ j.jaci.2006.11.671

73. Ricklin D, Hajishengallis G, Yang K, Lambris JD. Complement: a key system for immune surveillance and homeostasis. Nat Immunol (2010) 11:785-97. doi: 10.1038/ni.1923

74. Boshra H, Li J, Sunyer JO. Recent advances on the complement system of teleost fish. Fish Shellfish Immunol (2006) 20:239-62. doi: 10.1016/ j.fsi.2005.04.004

75. Caruso R, Warner N, Inohara N, Nunez G. NOD1 and NOD2: signaling, host defense, and inflammatory disease. Immunity (2014) 41:898-908. doi: 10.1016/j.immuni.2014.12.010

76. Wajant H GM, Scheurich P. TNF receptor associated factors in cytokine signaling. Cytokine Growth Factor Rev (1999) 10:15-26. doi: 10.1016/S13596101(98)00023-9

77. Li KM, Li M, Wang N, Chen YD, Xu XW, Xu WT, et al. Genome-wide identification, characterization, and expression analysis of the TRAF gene family in Chinese tongue sole (Cynoglossus semilaevis). Fish Shellfish Immunol (2020) 96:13-25. doi: 10.1016/j.fsi.2019.11.029

78. Yan X, Chen S, Huang H, Peng T, Lan M, Yang X, et al. Functional variation of IL-1R-associated kinases in the conserved MyD88-TRAF6 pathway during evolution. J Immunol (2020) 204:832-43. doi: 10.4049/jimmunol.1900222

79. Zou PF, Huang XN, Yao CL, Sun QX, Li Y, Zhu Q, et al. Cloning and functional characterization of IRAK4 in large yellow croaker (Larimichthys crocea) that associates with MyD88 but impairs NF-kappaB activation. Fish Shellfish Immunol (2017) 63:452-64. doi: 10.1016/j.fsi.2016.12.019

Conflict of Interest: The authors declare that the research was conducted in the absence of any commercial or financial relationships that could be construed as a potential conflict of interest.

Copyright (C) 2021 Zhou, Zhang, Ji, Shi, Ma, Luo and Wei. This is an open-access article distributed under the terms of the Creative Commons Attribution License (CC BY). The use, distribution or reproduction in other forums is permitted, provided the original author(s) and the copyright owner(s) are credited and that the original publication in this journal is cited, in accordance with accepted academic practice. No use, distribution or reproduction is permitted which does not comply with these terms. 